\title{
The Relationship of Personality Characteristics, Awareness, and Attitude in a Verbal Conditioning Situation
}

\author{
M. Austin Doherty \\ Loyola University Chicago
}

Follow this and additional works at: https://ecommons.luc.edu/luc_theses

Part of the Psychology Commons

\section{Recommended Citation}

Doherty, M. Austin, "The Relationship of Personality Characteristics, Awareness, and Attitude in a Verbal Conditioning Situation" (1965). Master's Theses. 1917.

https://ecommons.luc.edu/luc_theses/1917

This Thesis is brought to you for free and open access by the Theses and Dissertations at Loyola eCommons. It has been accepted for inclusion in Master's Theses by an authorized administrator of Loyola eCommons. For more information, please contact ecommons@luc.edu.

Copyright $\odot 1965$ M. Austin Doherty 
THE RELATIONSHIP OF PERSONALITY CHARACTERISTICS, AWARENESS, AND ATTITUDE IN A VEREAL CONDITIONIMO SITUAPION

$$
\text { by }
$$

Sister M. Austin Doherty, O.S.F.

A Thesis Submitted to the Faculty of the Graduate School of Loyola University in Fartial Fulfiliment of the Requirements for the Degree of Mastor of Arts

June 1965 


\section{LIPE}

S1ster M. Austin Doherty, O.S.F. was born in ChIcago, IIlinois, August 10, 1927. She graduated from Alvernia High School, June, 1945, and attended Loyola University part-time from 1945 to 1950 . In December, 1951, she entered the community of the School Sistera of St. Francis and was professed as a Religlous in June, 1954. At that time she also received the degree of Bachelor of Arts with a major in h1story from Alverno College, Milwaukee, Wisconsin. In June, 1960, she receired the degree of Master of Arts in history from Marquette University, Milwaukee, Wisconsin.

From 1954 unt1l 1963 she taught history in high school and college. In September, 1963, she granted leave of abeence from Alverno College for full-tine graduate study in psychology at Loyola University, Chicago, Illinois. 


\section{ACKNOWLEDGLENT}

The author wishes to acknowledge her gratitude to Dr. Ronald E. Walker whose advice was instrumental in the planning and analysis of the experiment which constitutes this thesis, and whose encouragement helped to make the entire venture a human experience. 
TABIIE OF CONTENTS

CHAPTER

PAGE

I. ImRODUCTION. ...................

II. REVIEN OF THE LITERATURE. . . . . . . . . 4

III. METHOD . ....................... 13

IV. RESULTS AND DISCUSSION. . . . . . . . . . 16

A. Conditioning date............ 16

B. Fersonality test data........... 24

1. Aware-Unavare groups

2. Groups which liked and groups which did not like the reinforcement

3. Aware-Like and A ware-Did not like groups

4. Unaware-Like and Unaware-Did not 21ke groups

7. Conclusions ................... 47

A. Conditioning data ........... 47

B. Personality characteristics....... 49

vI. Sumplat ........................ 53

rafardolos.................... 54

AFPEMICES.................... 58 


\section{INST OF TABLES}

T BLE

1. TRENO ANALISIS FOR VERBAL CONDITIONING DATA FOR EXPERTMEITAL, CONTROL I, AFB CONTROL II GROUPS. ..... 17

2. TREM ANLIISIS FOR VEREAL CONDITIONIMO DATM FOR AWARE, UNAWARE, CONTROL I, CONTROL II GROUPS ......... 19

3. TREND ANALYSIS FOR VERBAL CONDITIONING DATA FOR A-L, A -NI, U-L, U-KL GROUPS. ...............

4. TRED AMLYSIS FOR VERBL COMITIOMING DATA FOR L AMD NL GROUPS.

5. INTERCORRELATIONS FOR ALl VARIABLES FOR ALTARE GROUP . . . 28

6. INTERCORRELATIONS FOR ALL VARIABLES FOR UNAWARE GROUP . . 29

7. DIFFERENCES BETWEEN GROUPS ACCORDING TO ATTITUDE TOWARD REIMPORCEMENT (L AMD KL aROUPS) ............

8. DTFTERENCES BETWEEN L AND NL SUBJECTS ON PERSONALTTI TRATS

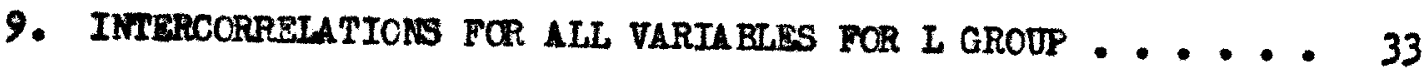

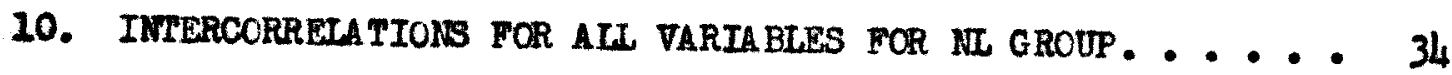

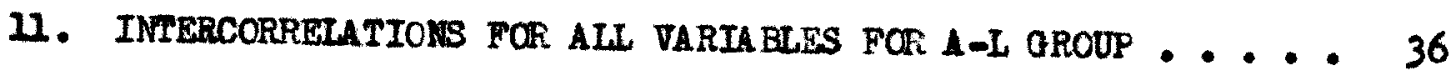

12. INTERCORRRLATIONS FOR ALL VARIABLES FOR A-ML GROUP. . . . 37

13. DIFFERENCES BETWEEN UNAWARE GROUPS ACCORDINO TO ATTITUDE TOWARD REINFCRCEMENT (U-L AND U-NL GROUPS)........ 42

14. DIPFERENCES BETWEEN U-L AND U-NL SUBJECTS ON PERSONALITY TRAITS.

15. INTERCORREHATIOUS FOR ALL VARIABLES FOR U-L GROUP ..... 45 16. IMTRRCORRELATIONS FOR ALI VARIABLES FOR U-ML GROUP. ... 46 
FIGURE

PAGE

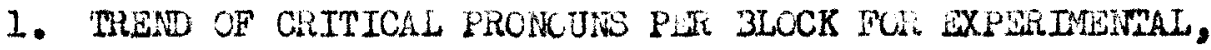
CONTROL I AND CONTROL II GROUPS. . . . . . . . 18

2. TREND OF CRITICAL PRONOUNS PER BLOCK FOF AWARE, UNAWARE, CONRROL I AND CUNTROL II GROUPS. . ......... 2 .

3. TREN OF CRITICAL PRONOUNS PER BLOCK FOF A-L, A-NL, U-I,

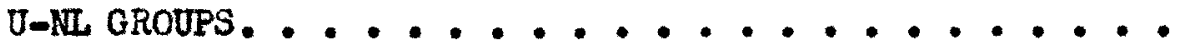

4. TREID OF CRITICAL PRONOUNS PAR BLOCK FOF I AND NL

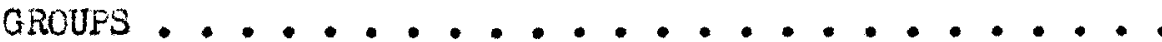




\section{CHAPTER I}

\section{INTRODUCTION}

Since the intial experiments of Taffel (1955) and Greenspoon (1955) the question of verbal conditioning, or learning without awareness, as it was originally called, has become increasingly more complex. In ten years of experimentation, the focus has shifted several times. Preoccupation with the phenomenon itself and related personality characteristics gave way before the quest of awareness as a concealed variable in the experimental situation. Concentration on levels of awareness and the derelopment of methods of assessing the subject's conscious avareness doninated the Ifterature during 1961 and 1962. More recently the focus has been on investigating the complex relationships between the subject's awareness, complexity of the task, examiner rariables, influence of instructions, and atmosphere of the experimental situation.

It will be recognized that most of these factors are peculiar to a human conditioning situation and yet most of the research is based at least implicitly on the Skinnerian paradigin of operant conditioning (Skinner, 1957). Although it is not possible to discover the level of the animal's "awareness" of the relationship between the conditioned operant (e.g. bar pressing) and the reinforcing stimulus (e.g. food pellet), it has been demonstrated that changes in the reinforcing atimulus do produce changes in 
the animal's behavior, and often according to a predictable, lawful pattern. In the analogous verbal conditioning experiments subjects increased their responses to the reinforcing stimulus without seeming to be aware of its relationship to the preceding conditioned operant. The relationship to animal operant conditioning seemed to be clearly demonstrated.

Primarily through the work of Spielberger and Dulaney, however, the role of awareness in the verbal conditioning situation was explored. Subsequent experiments indicated that where awareness had been carefully Investigated there was evidence that there was no learning without awareness.

These conclusions in turn have focused attention on the definitions of the two terms learning and awareness. Learning, in the verbal conditioning experiment, is operationally defined either as the emission of the reinforced response class, the unconditioned response in Skinnerian operant conditioning, or awareness of the correct contingency, recognition of the relationship between the conditioned operant and the reinforcing stimulus. At present for most inrestigators the accepted operational definition of Qwareness is verbalization of the correct contingency. The problem of eliciting this report without indueing awareness has proved to be a sensitive one in interviewing.

As Farber (1963) pointed out, however, in spite of the clarification of this relationship between awareness and learning, experiments did not give evidence of any clearcut relationship between improvenent in performance and ability to report the reinforcement contingency. Obvioualy there are other factors operating in these experiments which have not been 
sufficiently studied. It is reasonable to assume that among these factors are personality characteristics.

Differences in personality characteristics may be presumed to exist between those subjects who become aware and those who remain unaware in the experimental situation and also between those subjects whose awareness does not induce an increase in the reinforced response and those whose awareness is positively related to increase of the critical response.

Investigators interested in this area have attempted to specify the relationship between personality characteristics and verbal conditionability, treating the problem of awareness only incidentally or eliminating the profiles of aware subjects from statistical analysis. This is primariIy true of those investigators who hypothesized learning without awareneas. Among experimenters investigating the phenomenon of awareness very few have analyzed the subjects in terms of personality characteristics. Those who have did not discover significant differences between groups. In all these cases a restricted number of personality variables have been selected, either on an a priori basis or because of their relevance to a successful psychotherapeutic relationship. Results have been confusing, in many instances contradictory, and in general inconclusire.

The special focus of this thesis is an investigation of the personality variables of those subjects who do not become aware of the correct contingency in a relatively simple verbal conditioning experiment, or who, having become aware, do not improve their performance, as measured by an increase in the number of conditioned responses. 
Since the focus of this thesis is the relationship between awareness-unawareness and personality characteristics, the following review is Ifmited to articles and reports of experinents in this area. An appreciation of the extent and variety of research in this field can be gleaned from the number of lengthy review articles which have appeared in recent years. Among the most comprehensive are Greenspoon (1962), Krasner (1958), Salzinger (1959) and Williams (1964).

This review will consider first those experiments dealing with verbal conditioning and the personality characteristics of anxiety, autonomy, need for approval, sociability and others and, second, those experiments investigating awareness in a verbal conditioning situation. When awareness is not mentioned in the following experiments, it will indicate that no mention of this variable was made in the original report. Since anxiety plays a key role in interpersonal relationships more studies have investigated this aspect of personality than any other. Taffel's (1955) ploneer work and Sarason's (1958) study of neurotics and psychotics yielded a positive correlation between measures of anxiety and rate of verbal conditioning. In Sarason's study no $\underline{\text { s }}$ were aware of the correct contingency and only seven of 60 ss noticed the E's reinforcenent. 
Later experiments by Farber (1963), Levin (1961), and Eriksen, Kuethe and Sullivan (1958), however, failed to find any relationship between anxiety and conditioning; neither did they establish any relationship between anxiety and awareness. These contradictory findings may be due to differences in subjects--normals v8. neurotics and psychotics--and in measures of anxiety--Test Anxiety Questionnaire (Sarason, 1958), MAS (Farber 1963; Levin, 1961; Taffel, 1955) and Psychasthenia Scale of the MPI (Eriksen et al., 1958).

On an a priori basis, autonomy is believed to be negatively related to conditionability generally. Investigations by KIrman (1958) and Levin (1961) have failed to establish such a relationship. Babledelis (1961) reported a signfficant negative correlation only between autonomy and verbal conditioning when positive self-references were reinforced but not when negative self-statements were reinforced. Her results contrasted with Rogers' (1960) finding of a significant conditioning effect for reinforced negative self-statements but not for positive self-statements.

Vestre (1962) in a study of hospitalized schizophrenics found a significant negative correlation between persons high on the Autonomous Scale of Edwards Personal Preference Schedule and conditionability but his results are open to question because of the arbitrary score by which he chose to establish conditloning (increment across blocks as opposed to decrement across blocks).

Elimination from statistical analysis of the profiles of four S who were aware of the correct contingency also makes it difficult to compare his results with other investigations. 
Although Cairns and Lewis (1962) found no statistical evidence of conditioning, they discovered a significant relationship between dependency scores and increases in the critical response; and between dependency scores and positive attitude toward reinforcement. In spite of the latter linding, however, there was only a minimal increase in emission of the critical response for these subjects. Unfortunately Cairns and Lewis do not mention the existence of awareness among their subjects. Since the critical response was either a verb denoting aggression or a verb denoting dependency, the analysis of awareness might have clarified the relationships existing between the dependency variable and conditioning.

Closely related to these findings is the result reported by Gelfand (1962) that self-esteem and conditioning are negatively correlated. Gelfand's design included experiences of success and fallure for the experimental groups which yielded the finding that subjects exposed to experiences inconsistent with their customary self-evaluations (high selfesteem-failure and low self-esteem-success) showed significantly more verbal conditioning than those whose experiences were conslatent with selfattitudes. Unfortunately neither the question of anxiety nor the problem of awareness was included in this study.

Related to the above studies of a negative relationship between autonomy and conditionability have been series of investigations into an alleged positive relationship between need for approval and conditionability. Results have been similarly confusing. Splelberger, Berger, and Howard (1963) found no correlation between the two but Marlowe (1963) and Crowne and Strickland (1961) discovered a significant positive correlation. 
In the Spielberger et al. (1963) experiment the status of the experimenters, who were graduate assistants, may have been a factor in the results. It was not possible for this group to evaluate statistically the relationship between need for approval and awareness but there was a "strong suggestion" that they ware not related.

In Marlowe's (1963) study no subjects were aware of the correct contingency although 27 of the 38 experimental subjects noticed the reinforcement and felt it signified interest or encouragement. In the Crowne-Strickland ( 1961 ) investigation the profiles of sixteen subjects who were judged to be aware were eliminated from the analysis. No differences were discovered between the high and low need for approval groups and awareness, although it is interesting to this investigator that 15 of the 16 aware subjects were from the condition which received a negative reinforcement.

In very recent study on this same variable Epotein (1964) discovered a complex relationshlp between need for approval, awareness, and the reinforced contingency--hostile and neutral verbs. All subjects conditioned except low need for approval on hostile verbs. More subjects in the low need for approval group were aware in the neutral verb condition and more high need for approval subjects were aware in the hostile verb group. It is posible to speculate that subjects were more sensitive to hostile responses and thus more aware.

A few studies on isolated personality variables have ylelded significant relationships in the predicted direction. Eysenck (1959), in an experiment with neurotics, found greater conditionability among 
introverts than among extroverts, as measured by the Maudsley Personality Inventory, although conditioning occurred in both. In a replication of the study with nomals, McDonnell and Inglis (1962) discovered that although the group as a whole conditioned, no significant correlation was found between the introversion-extroversion scores and conditioning scores. A possible explanation of the failure to replicate Eysenck's results may be found in the selection of the groups by McDonnell and Inglis. The latter experiment included a population normally distributed according to the Maudsley Scale whereas zysenck's group was dichotomized into extremes on the scale.

Krasner, Ulinann, Weiss and Collins (1961) found a positive relationship for their 48 male Ss between achievement via independence, as measured by the California Psychological Inventory, and conditioning and a negative relationship between hostility and conditioning, and a negative, but not significant, relationship between hypnotizibility and conditioning. Awareness was determined by an open-ended interview by the $\Xi_{\text {. }} O f_{\text {the }}$ three E8, two were male Ph.D.'s and one a female A.B. None of the female E's subjects was aware, nor did any condition. Among the aware Ss, the average number of critical responses--emotional words in a TAT-like situation--was slightly lower than among unaware Ss. All of these factors seem to indicate variable of attitude or atmosphere interacting with awareness.

In view of the difference noted above between results obtained by male and female Es, Sapolsky's (1960) discovery that interpersonal attractiveness and interpersonal compatibility between the experimenter and the subject were significantly related to rate of conditioning is especially 
interesting. A direct comparison of results is impossible, however, because of the different designs, a Taffel design and a TAT situation, and also because of Japolsky's employment of female Ss. No special analysis of

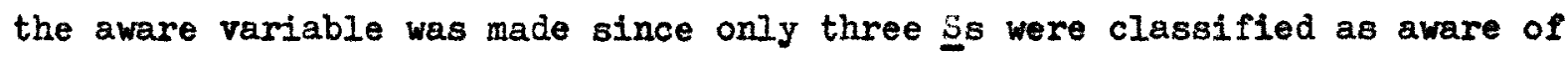
the correct contingency.

Three final studies are worthy of brief mention in this area. Haas (1962) concluded from his investigations that the subject's underlying emotional tone, whether positive or negative, could be manipulated by verbal conditioning. In a study by uinfree and Meyer (1963) on sociability it was discovered that $S \mathrm{~s}$ high on sociability and those low on sociability differed significantly in their conditionability to first person singular pronouns and first person plural pronouns. Both of these studies revealed that personality characteristics were a factor in conditioning but the study by Hetrick and Haas (1962) failed to find a significant relationship in the expected directions between verbal conditioning and ego strength, psychopathy, and depression.

Although the conclusions discussed above regarding the role of anxiety, autonomy and related characteristics are contradictory, there is enough evidence to indicate a complex involvement of these factors in the verbal conditioning situation. In exploration of a broader spectrum of personality characteristics and their interactions with conditioning and awareness would seem to be called for at this time.

In the specific area of awareness and verbal conditioning Dulaney's (1961) discussion of the influence of the subject's own hypothests regarding reinforcement contingencies focused attention on the mediating 
properties of these hypotheses. In view of this active role of the aware subject, the possibility of conditioning in the skinnerian operant sense was thus called into question. The role of awareness itself became a subject of intensive study, particularly by Eriksen (1962) and Spielberger (1962) and their colleagues.

Eriksen's (1962) experiments ylelded results which indicated that there was no loarning without awareness. In elaborating his theory that where cues and reinforcement are salient enough to produce learning they will not escape detection by awareness, he also holds the position that attention is inextricably interwoven with the concept of awareness.

In investigating the problem of awareness, Spielberger (1962) and Levin (1961) have focused on the necessity of an intensive interviow of the subject to ascertain his degree of awareness. According to Levin (1961) the brief interview, the usual criterion of awareness, was an insensitivo measure. Subjects judged aware by the brief interview did not differ significantly from controls. Only when the aware group was extended to include those classified as aware by means of the intensive interview did the aware and unaware groups differ from each other and from the control Groups.

More recent studies have attempted to study awareness directly by treating it as an independent variable. Weinstein and Lawson (1963), manipulating awareness in three groups, discovered that there was no learnIng without awareness. They also discovered that "fully aware" Ss, who had been informed of the correct contingency during the experiment, did not reveal this awareness uniformly on several measures of detection. Krasner 
and UIImann (1963) found that reports of awareness were influenced by mild increases in threat or stress. How this is related, if at all, to the personality trait of anxiety as usually measured was not discussed.

In several of the above studies it is evident that a factor besides awareness is operative. When the subject is ego-involved, the prediction of verbal conditioning becomes more complex. Ievin (1961) reported that aware $\mathrm{S} s$ who evaluated the reinforcement positively achieved higher conditioning scores. The attitude of unaware Ss was not analyzed since they did not condition.

In the Krasner and VIlmam(1963) study referred to above, those $\underline{s}$ conditioned who were told that the emission of statements regarding personal problems--the contingency being reinforced in a TAT-Iike task--was an

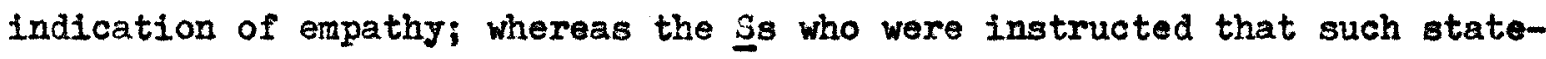
ments revealed the $\underline{S}$ 's own personal problems did not condition. This same finding was reported by Bkman, Krasner and UIImann (1963) who also discovered that those Ss who felt more threatened in the situation revealed a greater incidence of awareness of the correct contingency.

From this discussion it is evident that there are still many unanswered questions about the relationships between personality characteristics, verbal conditioning, awareness, and attitude of the subject. In view of what has been reported in the literature the most promising leads to be explored seem to lie in the interaction of various personality characteristics in subjects who can be differentiated along lines of awareness and attitude toward reinforcement. This is the area of investigation in this thesis. 
The purpose of this experiment is to study conditionability of femele $S_{s}$ in the simple Taffel design which is most effective for the assessment of awareness. Females were chosen because research has indicated that if they become aware they are more likely than male $\underline{S}$ to act on their awareness (Spielberger, Berger, and Howard, 1963).

It is hypothesized that aware $\underline{S}$ will be distinguished from unaware Ss by less anxiety, higher rating on the digit-span scale, higher egostrength and greater self-sufficiency. The relationship of anxiety to conditioning is a complex one and the evidence is contradictory. It is assumed here that a less anxious person would be more capable of attending to the environment than a highly anxious person and thus would be more aware of the relationships exfsting between the $\mathrm{I}^{\prime} \mathrm{s}$ behavior and his own. Since it is believed that high score on the WAIS digit-span scale is related to attention and inversely related to anxiety as clinically measured (Wechsler, 1958), a high score on this scale should characterize the aware S8. Higher ego-strength and greater self-sufficiency are believed to be related to the ability to deal with one's enviroment and thus are assumed to include cognizance of factors operating within the environment.

Concerning other personality characteristics being tested, it is expected that there will be some, hitherto unexplored, which will differentiate the subgroups according to avareness and attitude. In this sense the present investigation is exploratory. 
CHAPTER III

MEIHOD

To Inrestigate various relationohips between aware and unavare Ss In a rerbsl conditioning situation 120 female Ss were chosen to particlpate In an experiment based on Taffel's (1955) design. This relatively simple design was chosen in preferenoe to a more complex one because awareness is more readily detected with Taffel's procodure. Six weeks prior to the experiment the Ss took the Nicolay-Walker (1963) Personal Reaction Schedule and Cattell's (1964) $16 \mathrm{PF}$ Questionnalre. Throughout the experiment anonjmity was preserved. Bach $\underline{\mathrm{S}}$ chose a pseudonym by which she was known to the E. It was hoped that anonymity would insure greater frankness in answering the questions on the personality tests and would create a more relaxed atmosphere during the experiment.

\section{Subjects}

The Ss were 120 female novices in a religious community. Their ages ranged from 19 to 26 , with a mean age of 20.8 . They were randomly assigned to three groups: Experimental (G), $60 \mathrm{Ss}$; Control I (C-I) - no reinforcement, 30 Ss; Control II (C-II) - predetermined random reinforcement, 30 ss.

\section{Instruments}

The Nicolay-Walker Personal Reaction Schedule (PRS) was chosen to 
assess the personality variab?e of anxiety since the presence or absence of aisxiety seems to be a critical factor in awareness and conditionability. The PRS in addition to giving a general anxiety score provides a finer measure of anxlety in the following areas: Motor Tension; Object Anxiety; and Personal Inadequacy. In addition the Taylor (1953) MAS score and the K score of the MMFI (Hathaway and McKinley, 1951) are obtained from the particular form of this instrument which was used.

Cattell's 16 PF questionnaire was selected to assess personality variaties because it is considered a comprehensive measure of distinct personality factors. Since the area of personality variables is the special focus of this experiment, it was believed that this questionnaire would provide the best assessment of relevant aspects of personality.

In order to gather additional information on the phenomenon of awareness, the Digit-Span subtest of the WAIS was administered. Since this test is considered to correlate negatively with anxiety and to be a measure of attention, it was expected that it would be related to the aware-unaware continuum. This subtest was given to each $\underline{S}$ as part of the experiment. It immediately preceded the verbal conditioning procedure described below.

\section{Procedure}

The experimental apparatus consisted of 100 unlined white $3 \times 5$ cards. One hundred commonly used neutrally-toned verbs were selected, and in the middle of each card was typed a single verb in the past tense. Underneath each verb six pronouns--I, We, You, He, She, They--were typed in 
randion order.

The $\underline{S}$ was instructed to say the first sentence which came to mind containing the verb and beginning with any one of the pronouns. The pronoun used was recorded by the $E$ on a special data sheet (Appendix I). The operant rate for the pronouns was established during the first 20 trials, each card constituting a trial, when no reinforcement was given. During the next 80 trials the response of the $E$ varied according to the following groups:

Experimental Group (B): after every sentence beginning with I or We, the E administered the reinforcement "mm hmm" in a neutral but not uninterested tone.

Control Group I (C-I): no reinforcement was administered. Control Group II (C-II): the reinforcement "mm $\mathrm{hmm}$ " was administered after every seventh and twelfth sentence regardless of the pronoun used.

Following the experiment the $\underline{E}$ interviewed each $S$ according to an intensive post-conditioning interview schedule (Levin, 1961) (Appendix II). Ss in Control Group I were asked questions I through 8 only. On the basis of this questionnairs the $\underline{S}$ in the experimental group were judged to be aware (A) or unaware (U) of the correct contingency and to have liked (I) or been indifferent to or not liked (NI) the reinforcement. 


\section{CHAPTER IV}

\section{RESULTS AND DISCUSSION}

\section{Conditioning Data}

Edwards Trend Analysis (1954) was used to determine differences

between the experimental, control, and various experimental subgroups. For purposes of analysis the trials were divided into 5 blocks of 20 trials each. Table I shows the results of this analysis for the experimental and the two control groups; Figure 1 deplets the same data.

Although there was a significant difference over blocks, there was no significant difference among the three conditions. This was not unexpected in view of the fact that the aware-unaware variable was hypothesized as the critical factor in increase of response.

An interesting feature of this data was the decrease in performance during the fourth block for both reinforced groups. The non-reinforced Control I group, on the other hand, except for a barely perceptible decrease on the third block, showed a consistent increase in performance. Evidently the reinforcement, whether random or patterned, exerted an Influence on the $\underline{S} s^{\prime}$ behavior.

A Trend Analysis was also computed for the Aware $(N=27)$ and Unaware $(N=33)$ experimental groups, as determined from the post-conditioning interview, and the two control groups. This data is contained in Table 2; 
TABLE 1

TREND ANALYSIS FOR VIRBAL CONDITIONING DATA FOR EXPNRTMENTAL, CONRAOL I, AWD CONTROL II GROUPS

\begin{tabular}{|c|c|c|c|c|}
\hline Source & SS & $d f$ & MS & $\Gamma$ \\
\hline Methods & 49.31 & 2 & 24.65 & 1.14 \\
\hline $\begin{array}{l}\text { Pooled SS ( } \mathrm{b} \text { ) } \\
\text { in each method }\end{array}$ & $2517 \cdot 38$ & 117 & 21.51 & \\
\hline Blocks & 134.82 & 4 & 33.70 & $7 \cdot 5 * *$ \\
\hline Methods x Blocks & 143.86 & 8 & 17.98 & $3.9 * *$ \\
\hline $\begin{array}{l}\text { Pooled SS } x \text { Blocks } \\
\text { interaction }\end{array}$ & 2105.00 & 468 & 4.5 & \\
\hline Total & 4950.37 & 599 & & \\
\hline
\end{tabular}

**Significant at .01 level 


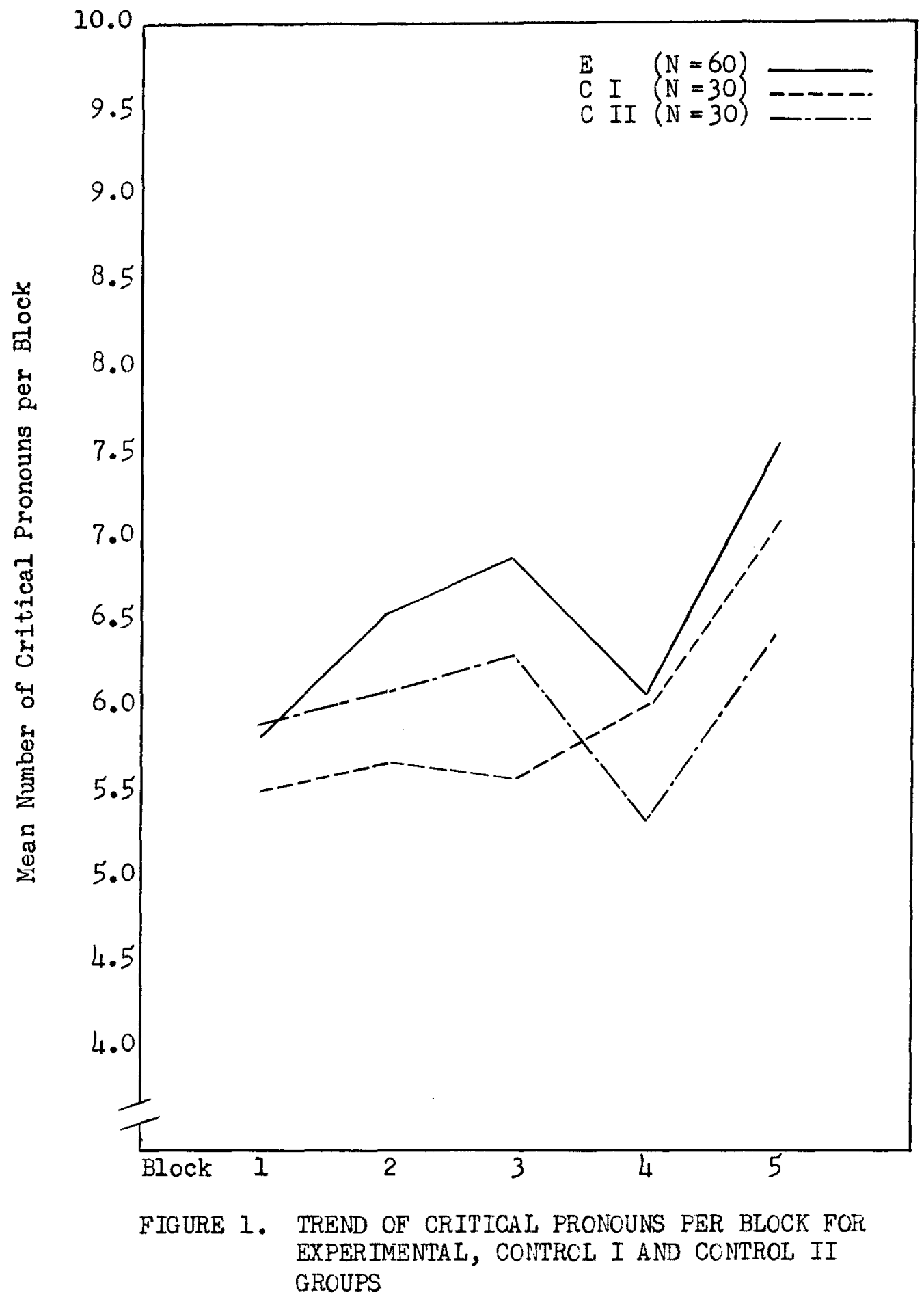


TABIN 2

TREND ANALYSIS FOR VERBAL CONDITIONING DATA FOR AWARE, UNAWARE, CONTROL I, CONTROL II GROUPS

\begin{tabular}{lrrrr}
\hline \multicolumn{1}{c}{ Source } & SS & df & MS & . \\
\hline Methods & 51.19 & 3 & 17.06 & .83 \\
$\begin{array}{l}\text { Pooled SS (b) } \\
\text { In each method }\end{array}$ & 2515.50 & 116 & 21.68 & \\
$\begin{array}{l}\text { Blocks } \\
\text { Methods x Blocks }\end{array}$ & 17.16 & 12 & 1.43 & .29 \\
Pooled SS x Blocks & 2331.70 & 464 & 4.98 & \\
interaction & & 4 & 33.70 & $7.5^{*}$ \\
Total & 4950.37 & 599 & & \\
\hline
\end{tabular}

* Significant at .01 level 
Figure 2 is a graphic representation of this same data.

Contrary to predictions there was no statistical difference between these groups, except in blocks. The unaware group actually had a lower mean average on the fifth block than the non-reinforced control group (C-I). The decrease in performance by the experimental group on the fourth block seems to be accounted for largely by the aware group, which fell beIow the performance of the unaware and Control I groups and performed equal to the initial operant rate. Some possible reasons will be advanced for this after the analysis of the correlations between personality factors and conditioning data.

An additional breakdown of the aware and unaware groups based on attitude toward the reinforcement yielded the four subgroups mentioned earlier: Awere and liked the reinforcenent (A-I); Aware and were indifferent to or did not like the reinforcement ( $A-N L$ ); Unaware and liked the reinforcement $(U-I)$; and Unaware and were indifferent to or did not like the reinforcement $(U-N L)$. The analysis for these groups is contained in Table 3; Figure 3 depicts the same data graphically. An F-score of 2.78 is needed for significance at the .05 level with 3 and $56 \mathrm{df}$. The F-8core of 2.51 was close enough to the required score to warrant the calculation of t-tests on the data. A significant difference was found between the $A-L$ and $A-N L$ groups for the fourth block (.01 level; $\underline{t}=2.59$ ), fifth block $(.05$ level; $t=2.24)$ and total blocks $(.05$ level; $t=2.56)$.

Since it was evident that the factor of attitude was operating on the conditioning scores a final analysis was performed on the data for those Ss in the Experimental group who liked the reinforcement (I) and 


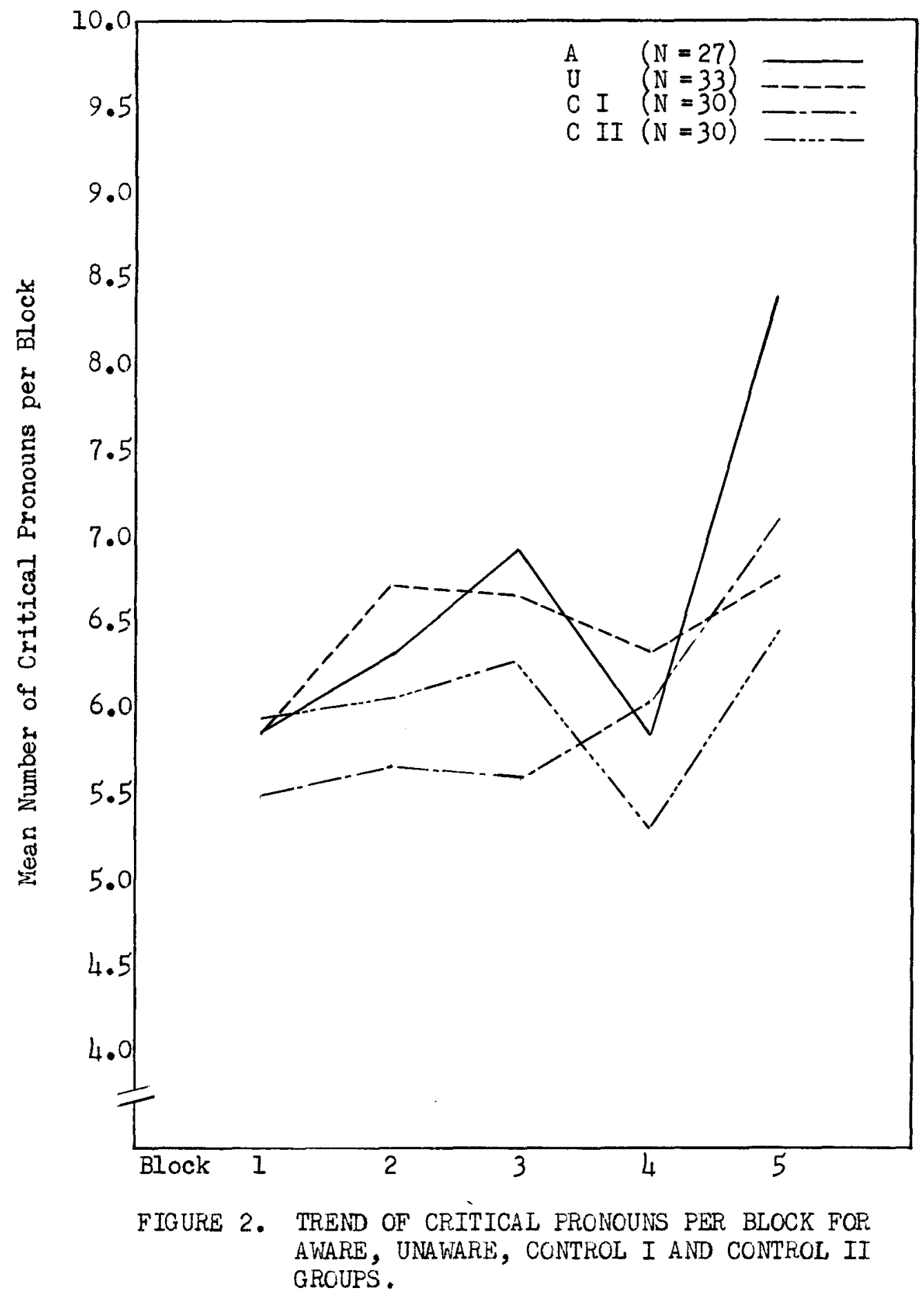




\section{TABLE 3}

TREND ANALYSIS FOR VERBAL CONDITIONING DATA FOR A-I, A-NL, U-I, U-NL GROUPS

\begin{tabular}{lrrrr}
\hline \multicolumn{1}{c}{ Source } & SS & df & MS & F \\
\hline Methods & 131.26 & 3 & 43.75 & 2.51 \\
$\begin{array}{l}\text { Pooled SS (b) } \\
\text { in each method }\end{array}$ & 972.94 & 56 & 17.37 & \\
Blocks & 98.57 & 4 & 24.64 & $4.90^{* *}$ \\
Methods x Blocks & 60.45 & 12 & 5.04 & 1.00 \\
Pooled SS x Blocks & 1121.86 & 224 & 5.008 & \\
interaction & 2384.08 & 299 & & \\
Total & & & & \\
\hline
\end{tabular}

* *Significant at .01 level 


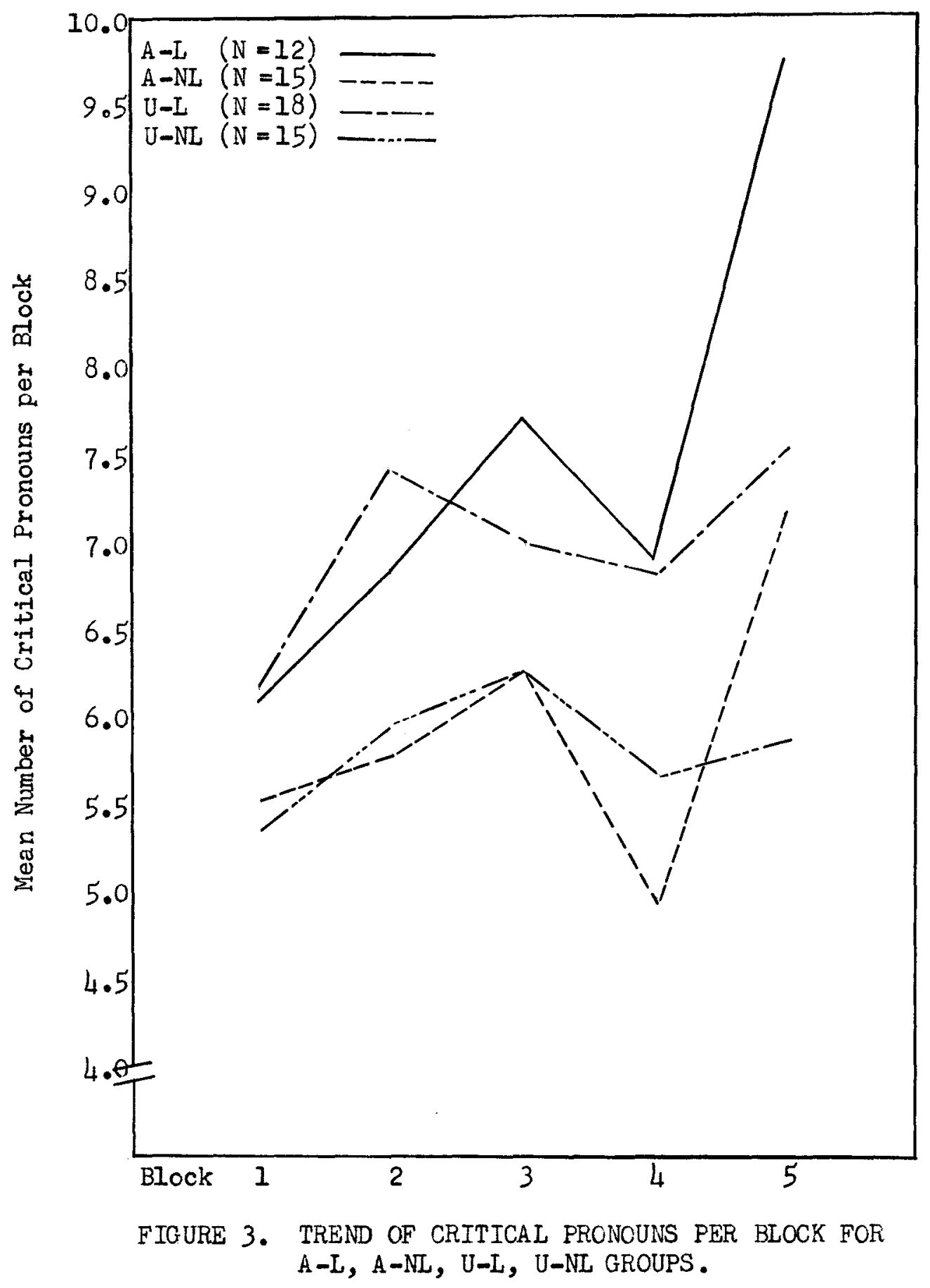


those who were indifferent to or who did not like it (NI). This data is contained in Table 4 and is presented graphically in Figure 4.

As indicated the group which liked the reinforcement ( $L$ ) and the group wich was indifferent to or did not like the reinforcement (NL) were significantly different from each other at the .01 level. The two groups also differed significantly from the two control groups $(F=2.8$; sigmificant at .05 level).

\section{Personality Test Data}

T-tests were computed for all personality characteristics for the following subgroups in the experimental group $(N=60)$ : Aware $(A)-$ Unaware (U); Iike (L)-Did Not Like (NL); Aware-Like (A-L)-Aware-Did Not Iike $(A-N L)$; Unaware-Iike $(U-L)$-Unaware-Did Not Iike (U-ML). Pearson Rho correlations were also computed for all varlables in the above groups.

\section{Aware-Unaware Groups}

On only one personality factor--PF G: Expedient-Conscientious-did the Aware $(N=27)$-Unaware $(N=33)$ groups differ significantly. The Unaware Group was more conscientious, persevering, rule-bound. (The means and standard deviations for the $A$ and $U$ groups respectively were $M=15.93$, $S D=2.21$ and $M=17.21, S D=2.59$. This difference was significant at the .05 level; $\underline{t}=2.02$ ). But this one difference out of a possible 29 could be accounted for by chance.

The personality characteristics for which predictions of differences were made were remarkably similar. For example, the mean scores in the A-U groups respectively were: Attention 11.82 and 11.55 ; Andety 
TABLE 4

TREND ANALYSIS FOR VERBAI CONDITIONING DATA

FOR I AND NL GROUPS

\begin{tabular}{lrrrr}
\hline \multicolumn{1}{c}{ Source } & \multicolumn{1}{c}{$S$ d } & df & MS & $F$ \\
\hline Methods & 126.55 & 1 & 126.55 & $7.5^{* *}$ \\
$\begin{array}{l}\text { Pooled SS (b) } \\
\text { in each method }\end{array}$ & 977.65 & 58 & 16.86 & \\
Blocks & 98.57 & 4 & 24.64 & $4.87^{* *}$ \\
$\begin{array}{l}\text { Methods x Blocks } \\
\text { Pooled SS x Blocks } \\
\text { interaction }\end{array}$ & 1173.76 & 232 & 5.06 & \\
Total & 2385.08 & 299 & & \\
\hline
\end{tabular}

"Significant at .01 level 


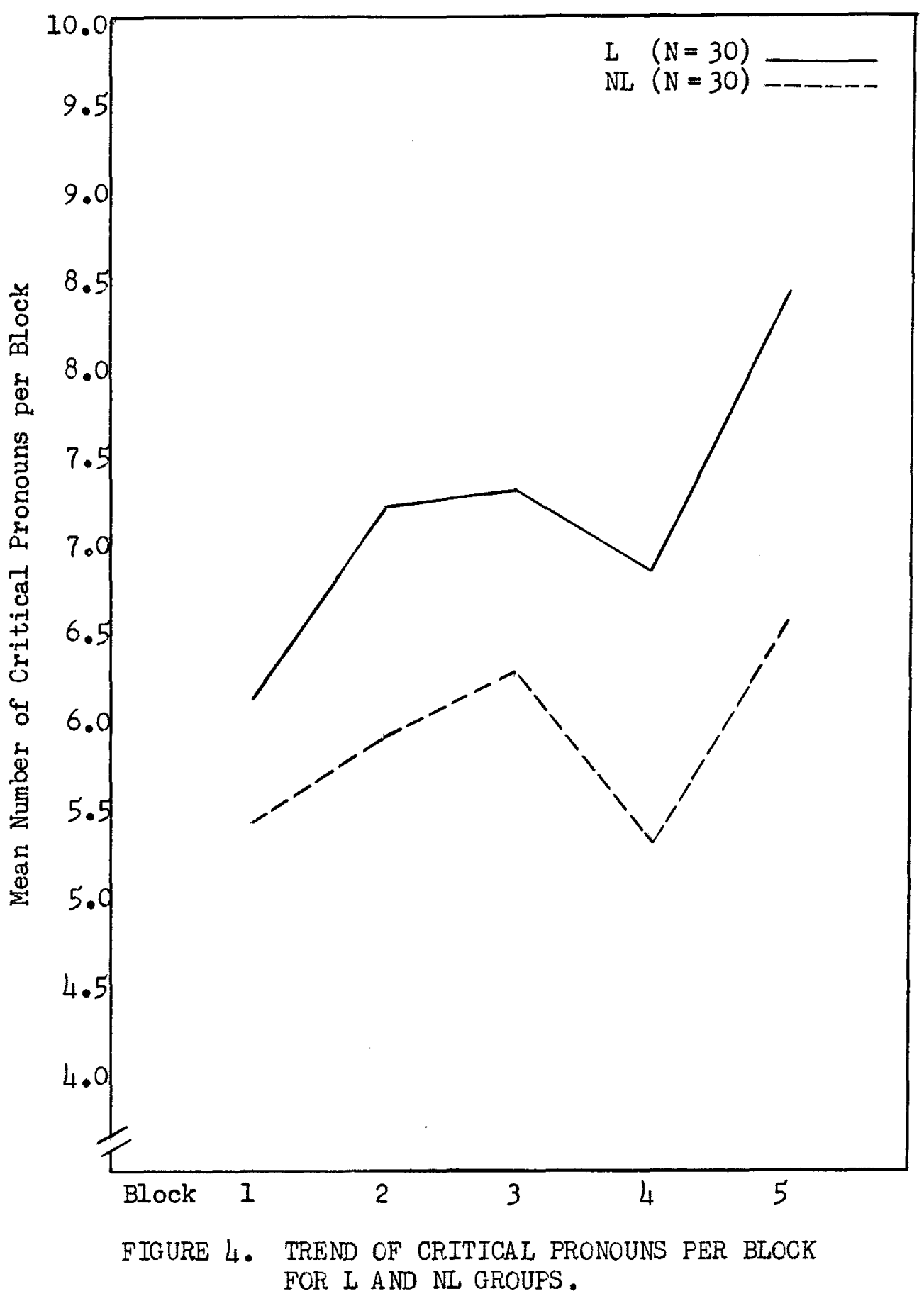


(FRS) 25.33 and 25.49; MAS 13.93 and 12.88; Higher Eigo-Strength 16.70 and 16.18 and Self-Sufficiency 10.26 and 9.76 .

With respect to the personality characteristic in which the $\mathrm{A}-\mathrm{U}$ groups differed significantly--Personality Factor G-there were significant differences between the intercorrelations. (See Tables 5 and 6 for the matrices of intercorrelations.) Factor G--Conscientiousness--correlated positively with anxiety in the Aware group and negatively with anxiety and self-sufficiency in the Unaware group.

The complex relationship between this factor and several other characteristics of the subjects will be discussed when the other analyses have been presented.

The variable of Attention was positively correlated with PF-Q4 (Tense, overwrought) $\underline{r}=.42, p<.05$; Dersonal Inadequacy (PRS-P) $\underline{\underline{x}}=.64$, $p<.01$; PRS Total, $\underline{\underline{r}}=.50, \mathrm{p}<.01$; and MAS, $\underline{r}=.48, p<.05$ for the Aware group. The last three $\underline{\underline{y}}^{\prime} \mathrm{s}$ were significantly different at the .05 level from the Unaware group. The correlations with attention in the Unaware group were Fersonal Inadequacy, $\underline{\underline{x}}=.08$, FRS TotaI, $\underline{\underline{x}}=-.03$, and MAS, $\underline{x}=-.03$.

\section{Groups which Liked and Did ilot Like the Reinforcement}

Considering these same sixty subjects according to their attitude toward the reinforcement, however, gave evidence of significant personality differences as well as the significant differences in conditioning discussed earlier.

of the 23 personality variables tested, these groups differed 
TABLE 5. INTERCORREIATIONS FOR ALL

VARIAB

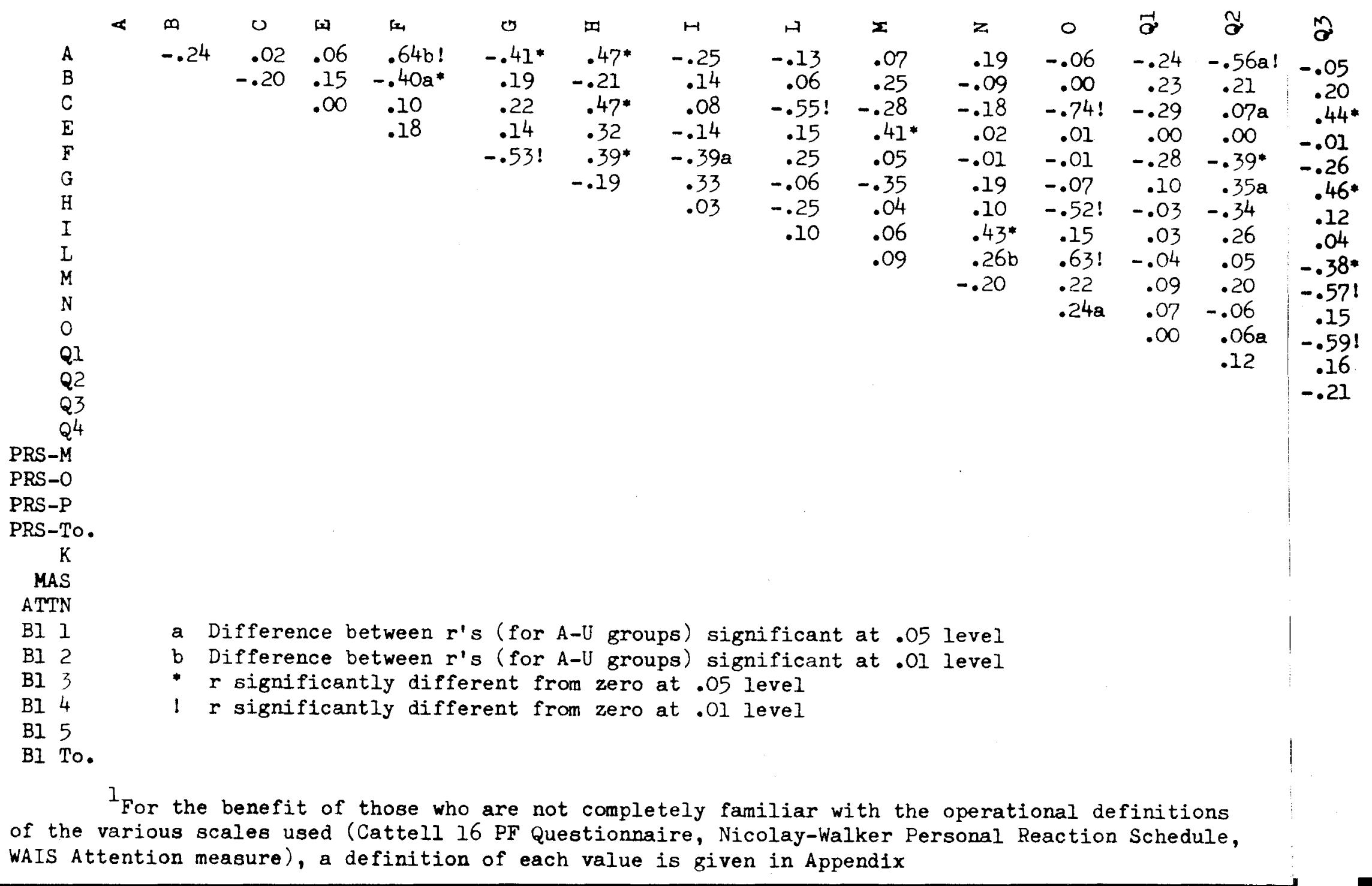
of the various scales used (Cattell 16 PF Questionnaire, Nicolay-Walker Personal Reaction Schedule, Atention measure), a definition of each value is given in Appendix 


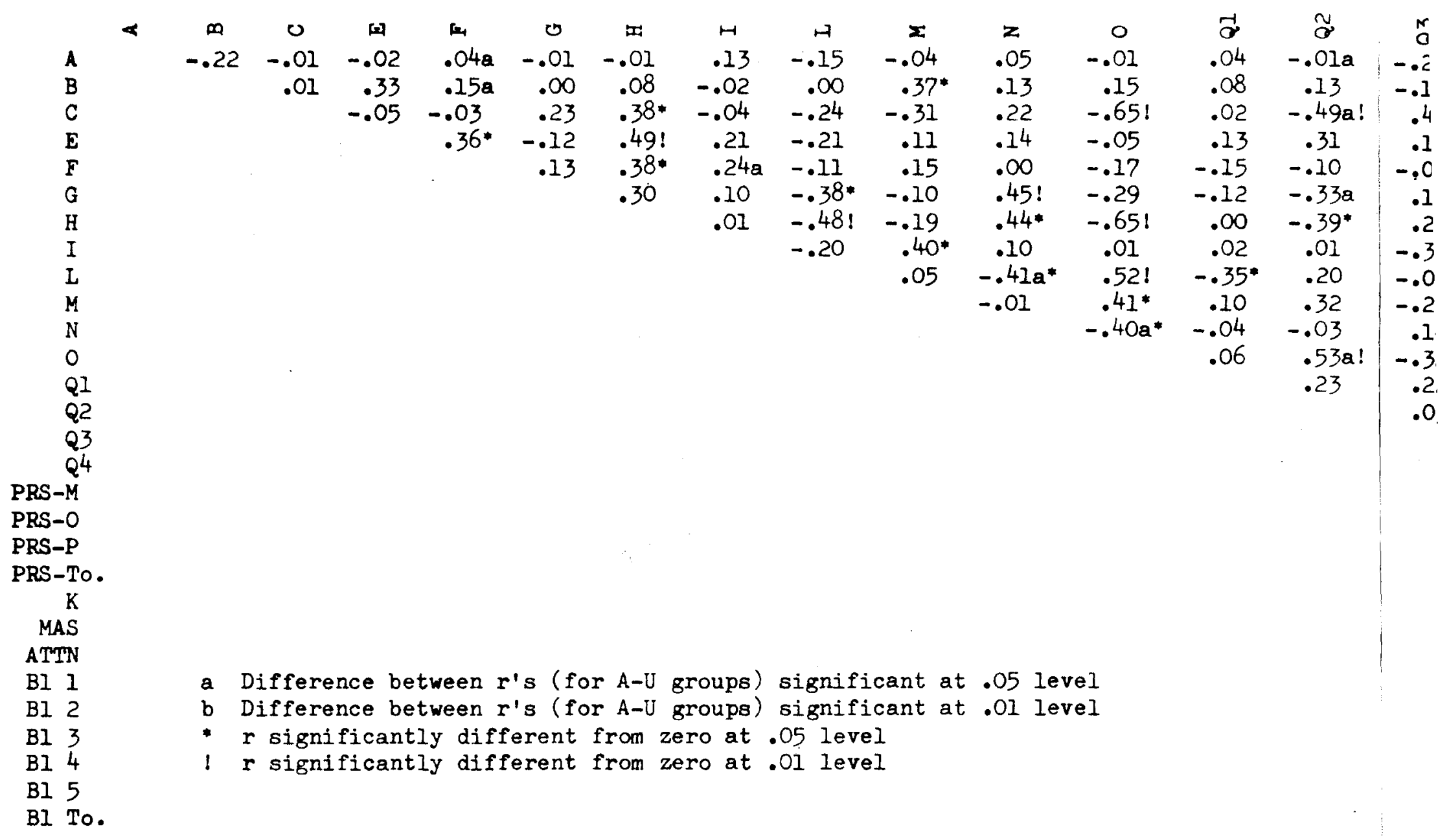


$R$ ALL VARIABLES FOR UNAWARE GROUP ( $N=33)$

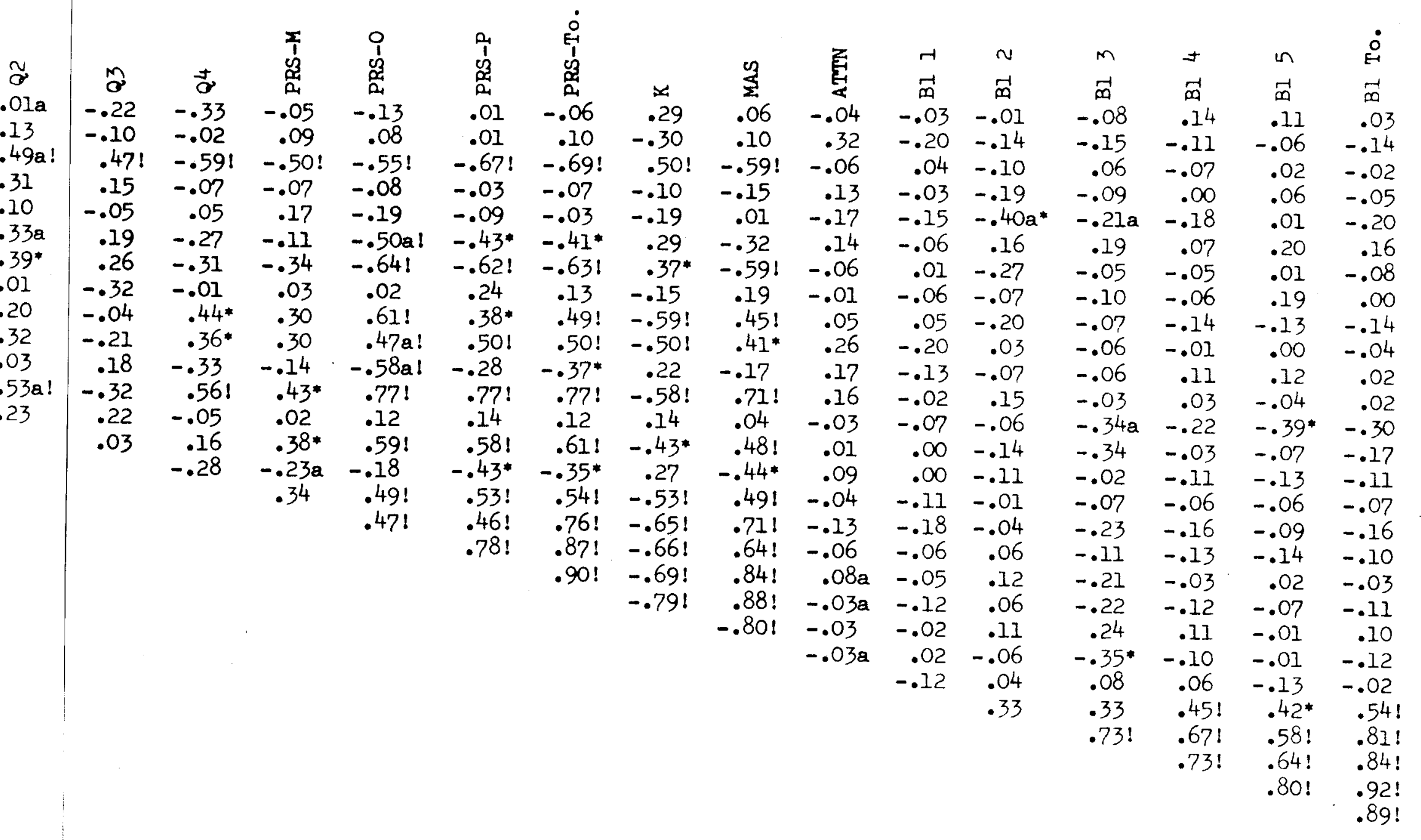


on 13. I-test analyses of this data are contained in Table 7. Drawing upen the characteristics differentiating the two groups, the description contained in Table 8 was formulated. Where the differences fall within the average range as designated by Cattell's Sten system, or the Nicolay-halker norms, this has been noted in order to indicate which scores actually deviate from average norms as well as which scores differ from each other in these two groups.

In the analysis of the interccrrelations among all variables, the most striking differences occur in the correlations between various anxiety measures and the blocks of trials. For the Ss who liked the reinforcement, and who obtained average scores on the anxiety measures, these scores correlated negatively with trial scores. Of a possible 42 correlations, 15 are significantly difierent from zero at the .05 level and 4 at the .0I level. For the Ss who did not like the reinforcement, and whose anxiety scores are below average, the correlations between these scores and trial scores are consistently positive but low and not significant. Highteen of the 42 correlations are significantly different frow each other in the two groups: 12 at the .05 level and 6 at the .01 level. (These scores are contained in the intercorrelation matrices, Tables 9 and 10.)

A comparison of these correlations with the Aware-Unaware groups shows that the correlations for the Unaware Group are consistently negative, although low and not significant. Except for the failure to achieve significance, this tendency is similar to the I Group. The trend in the Aware group is similar to the NL group, except for an interesting 


\section{TABLE 7}

DIFTBREMUES BETWEHN GROUPS ACCORDIMT TO ATTITUDE TOWARD REIRFORCEMEATI (L AND NL GROUPS)

\begin{tabular}{|c|c|c|c|c|c|}
\hline \multirow[b]{2}{*}{ Varlable } & \multicolumn{2}{|c|}{$\mathbf{L}$} & \multicolumn{2}{|c|}{ ML. } & \multirow[b]{2}{*}{$\mathrm{x}-\mathrm{score}$} \\
\hline & Mean & $S D$ & Mean & $\mathrm{SD}$ & \\
\hline $\begin{array}{l}\text { PF-A } \\
\text { PF-B } \\
\text { PF-C } \\
\text { PF-E } \\
\text { PF-F } \\
\text { PF-G } \\
\text { PF-B } \\
\text { PF-I } \\
\text { PE-I } \\
\text { PF-M } \\
\text { PF-N } \\
\text { PF-O } \\
\text { PF-Q1 } \\
\text { PF-Q2 } \\
\text { PF-Q3 } \\
\text { PF-Q4 } \\
\text { PRS-M } \\
\text { PRS-0 } \\
\text { PRS-P } \\
\text { PRS-Total } \\
\text { K } \\
\text { MAS } \\
\text { ATMN. } \\
\text { Block } 1 \\
\text { Block } 2 \\
\text { Block } 3 \\
\text { Block } 4 \\
\text { Block } 5 \\
\text { Total Bl. }\end{array}$ & $\begin{array}{r}10.43 \\
9.67 \\
15.30 \\
7.73 \\
13.17 \\
16.23 \\
10.63 \\
13.73 \\
7.47 \\
13.00 \\
8.07 \\
14.57 \\
8.60 \\
10.40 \\
10.17 \\
14.30 \\
11.30 \\
7.60 \\
11.60 \\
30.23 \\
16.63 \\
16.97 \\
11.30 \\
6.20 \\
7.23 \\
7.33 \\
6.90 \\
8.40 \\
36.10\end{array}$ & $\begin{array}{l}3.63 \\
1.52 \\
3.90 \\
3.69 \\
5.41 \\
2.49 \\
5.26 \\
2.37 \\
2.87 \\
3.67 \\
2.41 \\
4.98 \\
2.49 \\
2.37 \\
3.16 \\
3.51 \\
4.29 \\
3.19 \\
5.04 \\
10.28 \\
4.56 \\
8.94 \\
2.22 \\
1.52 \\
2.53 \\
2.48 \\
3.33 \\
4.60 \\
11.69\end{array}$ & $\begin{array}{r}10.30 \\
9.53 \\
17.53 \\
9.63 \\
12.43 \\
17.03 \\
13.87 \\
13.47 \\
5.80 \\
11.43 \\
9.03 \\
10.47 \\
9.27 \\
9.57 \\
12.10 \\
12.27 \\
8.00 \\
5.30 \\
7.30 \\
20.60 \\
18.93 \\
9.73 \\
11.53 \\
5.50 \\
5.93 \\
6.33 \\
5.37 \\
6.57 \\
29.70\end{array}$ & $\begin{array}{l}3.61 \\
1.34 \\
3.85 \\
3.61 \\
4.76 \\
2.45 \\
5.45 \\
2.43 \\
2.60 \\
2.97 \\
2.22 \\
4.64 \\
2.56 \\
3.41 \\
2.52 \\
3.78 \\
3.12 \\
3.15 \\
3.48 \\
7.33 \\
4.01 \\
5.67 \\
2.17 \\
1.67 \\
2.39 \\
2.67 \\
2.19 \\
2.57 \\
8.52\end{array}$ & $\begin{array}{l}.14 \\
.38 \\
2.19 * \\
1.98 * \\
.52 \\
1.23 \\
2.31 * \\
.42 \\
2.35 * \\
1.80 \\
1.57 \\
3.25 * * \\
1.01 \\
1.08 \\
2.57^{*} \\
2.14 * \\
3.33^{*} * \\
2.74 * * \\
3.77 * * * \\
4.10 * * \\
2.04 * \\
3.69 * * * \\
.47 \\
1.67 \\
2.03^{*} \\
1.47 \\
2.07 * \\
1.87 \\
2.39 *\end{array}$ \\
\hline
\end{tabular}

Signiflcance:

* .05 level

**.01 level

*** .001 level 
TABLE 8

DIFFEREICES BETWEEN I AIDD NL SUBJECTS ON PERSORAIITY TRAITS

Description of Subjects

Factor S8: liked relnforcement Ss: dil not like reinforce. $T$ signif.

PF-C Av: emotional maturity Ab.av: emot. maturity $2.19 \quad .05$

PF-E Av: contoming-1miependent Ab.av: independent $1.98 \quad .05$ assertive

PF-H Av: shymbold W1thln av: range but $2.31 \quad .05$ more venturesome

PF-L Av: adaptable-opintonated Adaptable-trusting $2.35 \quad .05$

PF-0 Worryling, apprehensive Placld, self-assured $3.25 \quad 01$

$\begin{array}{llllll} & \mathrm{PF}-\mathrm{Q}_{3} & \mathrm{Av}: \text { careless of protocol- Within av. range but } & 2.57 & .05\end{array}$ self-dibclplined

more socialiy precise

$\begin{array}{lll}\text { Relaxed } & 2.14 & .05\end{array}$

PF-Q4 Av: relaxed-tense

Less tension $\quad 3.33 \quad .01$

PRS-M Av: motor tension

Less tension

$2.74 \quad .01$

PRS-P Av: personal inadequacy

Less feeling of personal inadequacy

$3.77 \quad .001$

Less anxiety

$4.10 \quad .001$

MAS Av: anxiety

Less anxiety

$3.69 \quad .001$

K(MPI) Av: defensiveness

Ab.av: defensiveness $2.04 \quad .05$ 
TABLE 9. INTERCORRELATIONS FOR ALL

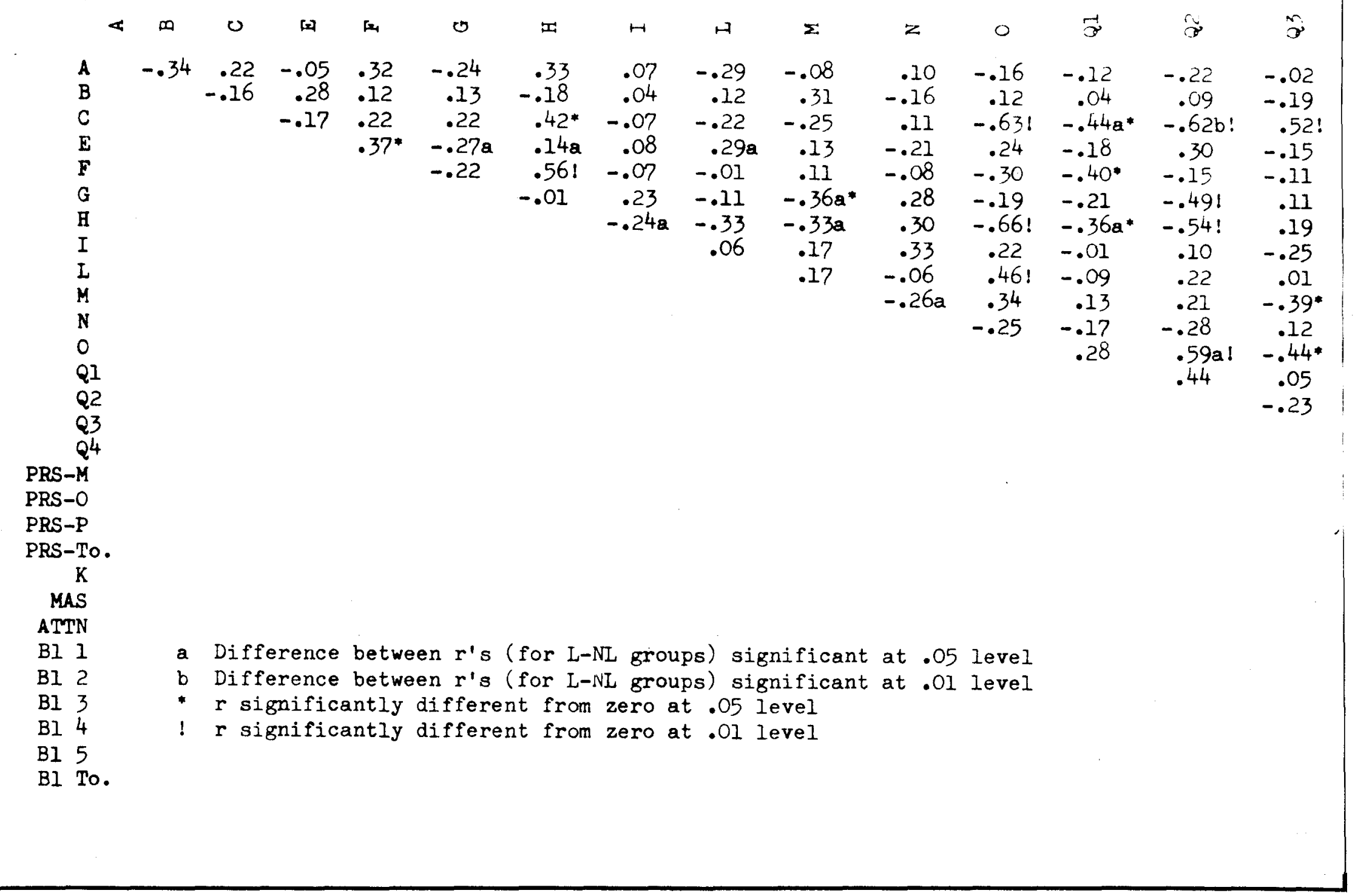


VARIABLES FOR L GROUP $(N=30)$

\begin{tabular}{|c|c|c|c|c|c|c|c|c|c|c|c|c|c|c|}
\hline$\stackrel{n}{3}$ & वे & 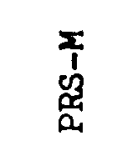 & 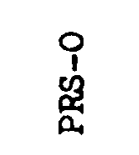 & $\begin{array}{l}A_{1} \\
\text { ơ } \\
\text { ơ }\end{array}$ & $\begin{array}{l}\dot{0} \\
\text { : } \\
\text { 品 } \\
\text { 员 }\end{array}$ & $x$ & $\stackrel{2}{\mathbf{2}}$ & 圛 & $\vec{r}$ & $\begin{array}{l}\sim \\
\tilde{m}\end{array}$ & ${ }_{m}^{m-1}$ & $\begin{array}{l}\vec{u} \\
\vec{x}\end{array}$ & $\begin{array}{l}n \\
\vec{n}\end{array}$ & $\begin{array}{l}\dot{0} \\
\vec{x}\end{array}$ \\
\hline $\begin{array}{c}-.02 \\
-.19 \\
.52 ! \\
-.15 \\
-.11 \\
.11 \\
.19 \\
-.25 \\
.01 \\
-.39 * \\
.12 \\
-.44 * \\
.05 \\
-.23\end{array}$ & $\begin{array}{c}-.21 \\
.13 \\
-.38 \\
.14 \\
-.01 \\
-.14 \\
-.19 \\
-.07 \\
.45 \\
.38 \\
-.31 \\
.47 ! \\
.09 \\
.25 \\
-.27\end{array}$ & $\begin{array}{c}-.18 \\
.24 \\
-.59 ! \\
.04 \\
.09 \\
-.19 \\
-.37 * \\
-.15 \\
.45^{*} \\
.22 \\
-.17 \\
.38^{*} \\
.30 \\
.43^{*} \\
-.33 \\
.37^{*}\end{array}$ & $\begin{array}{c}-.29 \\
.14 \\
-.61 ! \\
.10 \\
-.36 \\
-.33 \\
-.66 ! \\
.16 \\
.51 ! \\
.40 \\
-.30 \\
.80 a ! \\
.45 a \\
.64 a ! \\
-.20 \\
.49 ! \\
.48 !\end{array}$ & $\begin{array}{c}-.15 \\
.18 \\
-.61 ! \\
.04 \\
-.40 a^{*} \\
-.15 \\
-.63 ! \\
.30 \\
.35 \\
.35 \\
-.11 \\
.76 ! \\
.32 \\
.67 a ! \\
-.40^{*} \\
.50 ! \\
.43 * \\
.75 !\end{array}$ & $\begin{array}{c}-.20 \\
.19 \\
-.71 ! \\
.09 \\
-.23 \\
-.28 \\
-.63 ! \\
.13 \\
.50 ! \\
.39 * \\
-.19 \\
.78 ! \\
.37^{*} \\
.68 a ! \\
-.41 * \\
.53 ! \\
.75 ! \\
.87 ! \\
.87 !\end{array}$ & $\begin{array}{c}.40^{*} \\
-.37^{*} \\
.47 ! \\
-.19 \\
.01 \\
.05 \\
.02^{*} \\
-.01 \\
-.69 ! \\
-.35 \\
.04 \\
-.56 ! \\
-.06 \\
-.37 * \\
.26 \\
-.56 ! \\
-.61 ! \\
-.63 ! \\
-.64 ! \\
-.044 !\end{array}$ & $\begin{array}{r}-.11 \\
.16 \\
-. .64 ! \\
.10 \\
-.14 \\
-.07 \\
-.51 ! \\
.025 \\
.46 ! \\
.35 \\
.00 \\
.73 ! \\
.01 \\
.48 ! \\
-.50 ! \\
.51 ! \\
.68 ! \\
.58 ! \\
.83 ! \\
.85 ! \\
-.74 !\end{array}$ & $\begin{array}{c}.01 \\
.18 \\
-.17 \\
-.07 \\
-.31 \\
.03 \\
-.28 \\
.08 \\
.40^{*} \\
.17 \\
-.15 \\
.32 \\
.04 \\
.06 \\
-.22 a \\
.40^{*} \\
.14 \\
.37 a^{*} \\
.51 ! \\
.37 \\
-.33 \\
.30\end{array}$ & $\begin{array}{l}-.33 a \\
-.03 \\
-.08 \\
.01 \\
-.24 \\
.38 a^{*} \\
.01 \\
.05 \\
.06 \\
-.33 \\
.16 \\
-.09 \\
-.05 \\
-.01 \\
.24 \\
-.04 \\
-.22 \\
-.12 \\
.06 \\
-.15 \\
-.05 \\
-.04 \\
.19\end{array}$ & $\begin{array}{l}-.14 \\
-.28 \\
.23 \\
-.14 \\
-.35 \\
.16 \\
.03 \\
-.08 \\
-.34 \\
-.12 \\
.08 \\
-.41 a^{*} \\
-.02 \\
-.09 \\
. .32 a \\
-.30 \\
-.42 a^{*} \\
-.25 \\
-.27 \\
-.38 a^{*} \\
. .44 * \\
-.47 b ! \\
-.26 \\
. .19\end{array}$ & $\begin{array}{l}-.07 \\
-.17 \\
.40 b^{*} \\
.06 \\
-.13 \\
.11 \\
.21 \\
.09 \\
-.30 \\
-.11 \\
.12 \\
-.45 b^{*} \\
-.08 \\
-.18 \\
.35 a \\
-.33 a \\
-.50 b ! \\
-.38 * \\
-.45 a^{*} \\
-.56 b ! \\
. .43 b * \\
-.61 b ! \\
-.12 \\
.030 \\
.61 !\end{array}$ & $\begin{array}{r}.01 \\
-.23 \\
.12 \\
.01 \\
-.05 \\
.13 \\
.17 \\
.10 \\
-.28 \\
-.15 \\
. .30 \\
-.35 a \\
-.08 \\
.01 \\
.15 \\
-.16 \\
-.28 \\
-.31 \\
-.16 \\
-. .30 \\
.24 \\
-.30 \\
-.11 \\
.44 * \\
.65 ! \\
.69 !\end{array}$ & $\begin{array}{c}.12 \\
-.13 \\
.13 \\
-.01 \\
-.02 \\
.30 \\
.17 \\
.22 \\
-.16 \\
-.29 a \\
.50 a \\
-.37 a^{*} \\
-.37^{*} \\
-.11 \\
.17 \\
-.16 \\
-.24 \\
-.36 \\
-.19 \\
-.31 a \\
.18 \\
-.24 a \\
-.04 \\
.36 \\
. .47 ! \\
.52 ! \\
.78 a !\end{array}$ & $\begin{array}{c}-.05 \\
-.22 \\
.21 \\
-.02 \\
-.16 \\
.26 \\
.17 \\
.12 \\
-.27 \\
-.25 \\
.34 \\
-.44 b^{*} \\
-.20 \\
-.10 \\
.28 \\
-.25 \\
-.40 a^{*} \\
-.38 * \\
-.27 \\
-.43 a^{*} \\
.32 \\
-.42 a^{*} \\
-.11 \\
.50 ! \\
.74 ! \\
.78 ! \\
.93 a ! \\
.87 !\end{array}$ \\
\hline
\end{tabular}


TABLE 10. INTERCORRELATIONS FOR ALL

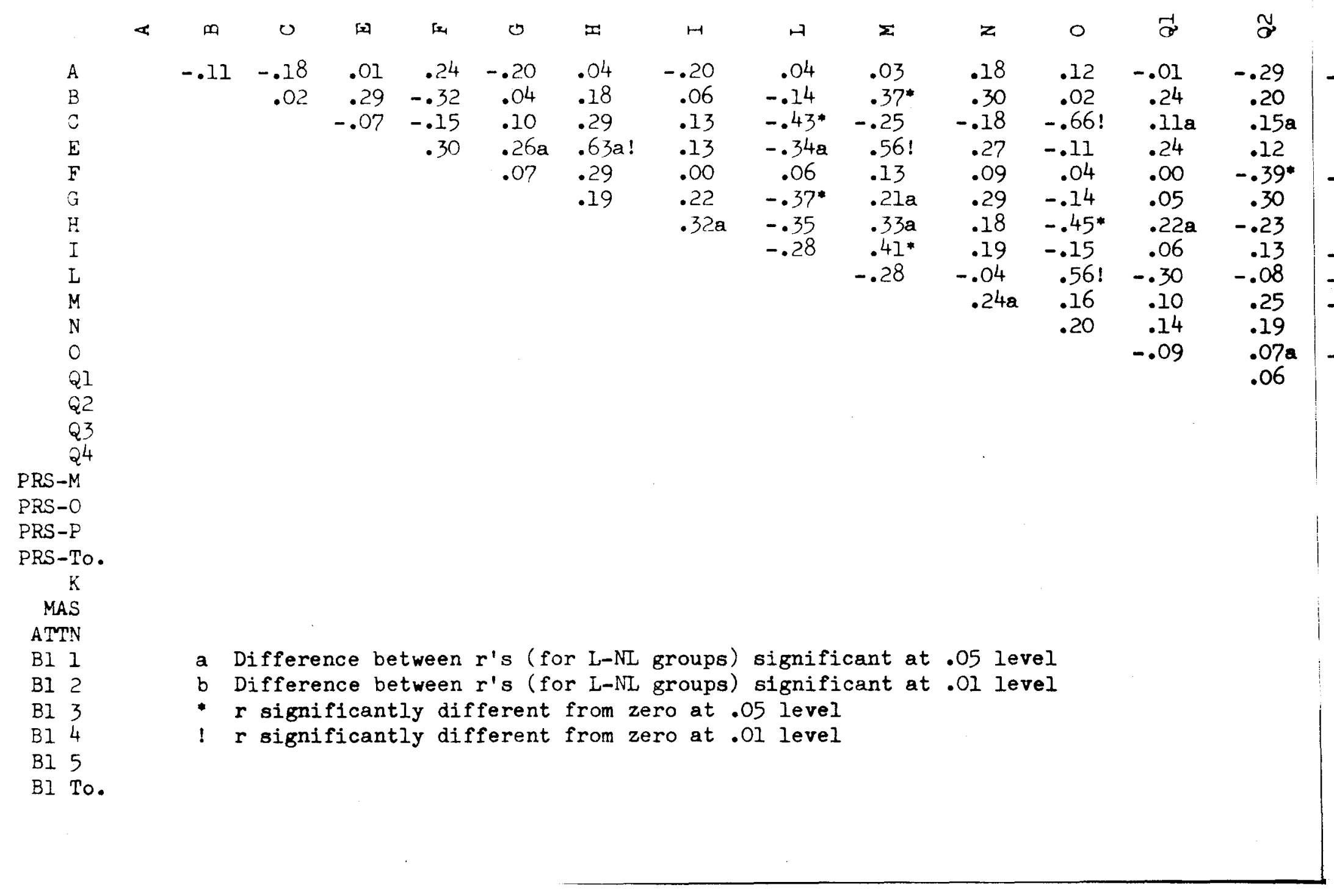


R ALL VARIABLES FOR NL GROUP $(N=30)$

\begin{tabular}{|c|c|c|c|c|c|c|c|c|c|c|c|c|c|c|c|}
\hline$\widetilde{\sigma}$ & $\stackrel{m}{a}$ & పే & 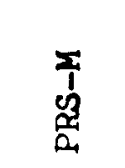 & $\begin{array}{l}0 \\
1 \\
0 \\
0 \\
0 \\
2\end{array}$ & 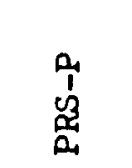 & 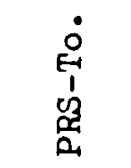 & $\forall$ & $\sum_{\Sigma}^{2}$ & $\underset{4}{2}$ & $\begin{array}{r}-1 \\
m\end{array}$ & $\begin{array}{l}\sim \\
\infty\end{array}$ & $m$ & $\begin{array}{l}\vec{A} \\
\vec{C}\end{array}$ & $\begin{array}{l}0 \\
\vec{a}\end{array}$ & $\dot{0}$ \\
\hline $\begin{array}{c}-.29 \\
.20 \\
.15 a \\
.12 \\
-.39 \\
.30 \\
-.23 \\
.13 \\
-.08 \\
.25 \\
.19 \\
.07 a \\
.06\end{array}$ & $\begin{array}{r}-.29 \\
.31 \\
.25 \\
.18 \\
-.15 \\
.35 \\
.02 \\
-.08 \\
-.018 \\
-.09 \\
.09 \\
-.18 \\
.31 \\
.16\end{array}$ & $\begin{array}{c}-.19 \\
-.18 \\
-.53 ! \\
.13 \\
.24 \\
-.26 \\
-.11 \\
-.21 \\
.41 * \\
.16 \\
-.07 \\
.45 * \\
-.13 \\
.02 \\
-.40^{*}\end{array}$ & $\begin{array}{c}.05 \\
-.09 \\
-.061 \\
.01 \\
.06 \\
.05 \\
-.05 \\
.13 \\
.08 \\
.50 ! \\
.31 \\
.33 \\
.00 \\
.18 \\
-.22 \\
.48 !\end{array}$ & $\begin{array}{c}-.13 \\
-. .20 \\
-.19 \\
-. .25 \\
-.03 \\
-.14 \\
-.54 ! \\
-.17 \\
.47 ! \\
-.08 \\
-.14 \\
.44 a \\
-.23 b \\
.19 a \\
.01 \\
.35 \\
.19\end{array}$ & $\begin{array}{c}.07 \\
.01 \\
-.62 ! \\
.05 \\
.04 a \\
-.08 \\
-.39 * \\
.07 \\
.37 \\
.15 \\
.07 \\
.62 ! \\
-.05 \\
.03 a \\
-.13 \\
.42 \\
.36 * \\
.49 !\end{array}$ & $\begin{array}{c}-.01 \\
-.12 \\
-.58 ! \\
.01 \\
.12 \\
-.08 \\
-.44 \\
.01 \\
.41 \\
.24 \\
.10 \\
.63 ! \\
-.12 \\
.17 a \\
-.15 \\
.55 ! \\
.68 ! \\
.74 ! \\
.83 !\end{array}$ & $\begin{array}{r}.14 \\
.10 \\
.44 * \\
-.19 \\
-.12 \\
.18 \\
.23 \\
-.05 \\
-.42 \\
-.35 \\
-.12 \\
-.57 ! \\
. .15 \\
-.18 \\
.15 \\
-.50 ! \\
-.41 * \\
-.59 ! \\
-.54 ! \\
-.68 !\end{array}$ & $\begin{array}{c}.03 \\
-.07 \\
-.41 \\
.02 \\
-.14 \\
-.14 \\
-.46 ! \\
.04 \\
.27 \\
.20 \\
.15 \\
.60 ! \\
-.05 \\
.40 * \\
-.19 \\
.53 ! \\
.56 ! \\
.50 ! \\
.71 ! \\
.79 ! \\
-.63 !\end{array}$ & $\begin{array}{c}-.22 \\
. .29 \\
-.12 \\
.22 \\
.00 \\
.40^{*} \\
-.07 \\
-.12 \\
-.08 \\
.09 \\
.14 \\
.16 \\
-.11 \\
.03 \\
.32 a \\
.00 \\
-.02 \\
-.19 a \\
.10 \\
-.05 \\
.06 \\
.04\end{array}$ & $\begin{array}{r}. .25 a \\
-.02 \\
.07 \\
.11 \\
-.10 \\
-.19 a \\
.07 \\
-.31 \\
-.07 \\
-.06 \\
-.31 \\
-.18 \\
.14 \\
-.26 \\
.08 \\
-.14 \\
.01 \\
-.14 \\
-.020 \\
-.15 \\
.14 \\
-.16 \\
-.19\end{array}$ & $\begin{array}{c}.22 \\
.12 \\
-.10 \\
.11 \\
.08 \\
.12 \\
-.08 \\
-.24 \\
-.19 \\
-.01 \\
.16 \\
.16 a \\
-.16 \\
-.01 \\
-.24 a \\
.15 \\
.19 a \\
.04 \\
.17 \\
.18 a \\
-.04 \\
.19 b \\
.09 \\
.25\end{array}$ & $\begin{array}{c}.35 \\
-.08 \\
-.38 a^{*} \\
.15 \\
.15 \\
-.04 \\
.08 \\
-.26 \\
.16 \\
.13 \\
.10 \\
.31 b \\
-.08 \\
-.34 \\
-.26 a \\
.02 a \\
.027 b \\
-.01 \\
.09 a \\
.15 b \\
-.26 b \\
.06 b \\
-.04 \\
.33 \\
.52 b\end{array}$ & $\begin{array}{r}.48 ! \\
.11 \\
-.26 \\
.24 \\
-.14 \\
.10 \\
-.01 \\
-.32 \\
-.19 \\
.03 \\
.11 \\
.19 a \\
-.23 \\
-.01 \\
-.11 \\
.03 \\
.06 \\
-.16 \\
.04 \\
-.02 \\
.09 \\
.11 \\
.20 \\
.27 \\
.571 \\
.491\end{array}$ & $\begin{array}{c}.25 \\
.24 \\
-.21 \\
.28 \\
-.27 \\
-.05 \\
-.02 \\
-.09 \\
.02 \\
.25 a \\
-.07 a \\
.28 a \\
.02 \\
.14 \\
-.06 \\
-.02 \\
.25 \\
.05 \\
.28 \\
.26 a \\
-.24 \\
.33 a \\
.01 \\
.45 * \\
.42 * \\
.471 \\
.45 a *\end{array}$ & $\begin{array}{c}.42 \\
.10 \\
-.25 \\
.24 \\
-.07 \\
-.01 \\
.01 \\
.22 \\
-.04 \\
.10 \\
.02 \\
.24 b \\
-.10 \\
-.17 \\
-.18 \\
.07 \\
.23 a \\
-.05 \\
.13 \\
.14 a \\
-.11 \\
.16 a \\
.02 \\
.57 \\
.76 ! \\
.79 ! \\
.76 a \\
.77 !\end{array}$ \\
\hline
\end{tabular}


and consistent difference; the correlations between Anxiety and Block 2 are negative rather than positive for the Aware group.

\section{Aware-Iike and Aware-Did Not Like Groups}

Analysis of the data according to attitude and awareness-unawareness was undertaken in an attempt to clarify the differences already noted in the above discussions.

In the $A-I$ and $A-N L$ groups the only significant differences were in the Anxiety scores: PRS-Motor Tension, Personal Inadequacy, and Total PRS. The scores of the A-NL group were significantly lower than the A-I group, whose scores fell within the average range according to previous studies with this instrument. This would be expected since the AwareUnaware groups did not differ from each other whereas the I and NL groups showed significant differences in this area; the NL group registered scores lower than average.

It is, however, in the analysis of the intercorrelations (Tables 11 and 12) with all other variables that differences are manifested. These appeared in Factor A--outgoing, sociable--a factor which did not differentiate either the $h-U$ or I-In groups when analyzed separately. In Factor a eleven of the 28 intercorrelations were significantIy different for the A-I and A-NL groups. Factor A scores for the subjects who liked the reinforcement $(A-I)$ were negatively correlated with PF-B, Intelligence; PF-I, Being Opinionated; PF-O, Apprehension; PRS Motor Tension; PRS Personal Inadequacy; PRS Total; MAS; Block $I$ and Total Blocks, and positively correlated with $P F-C$, imotional Maturity, and $K$ (MMPI). 
TABLE 11. INTERCORRELATIONS FOR ALL

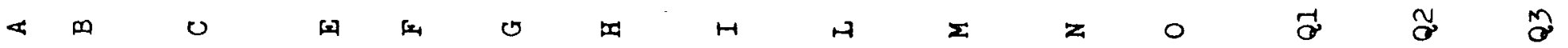

$$
\begin{aligned}
& \begin{array}{lllllllllllllll}
-.64 a^{*} & .70 b^{*} & -.16 & .72 ! & -.50 & .77 ! & -.25 & -.59 a^{*} & -.08 & -.08 & -.60 a^{*} & -.43 & -.55 & .12
\end{array}
\end{aligned}
$$

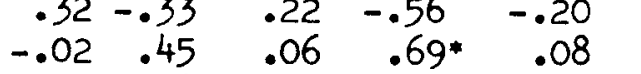

$$
\begin{aligned}
& \begin{array}{llll}
.28 & -.04 & .14 & .00 \\
-.65^{*} & .62^{*} & -.25
\end{array} \\
& \begin{array}{rr}
.22 & .09 \\
-.44 & -.37
\end{array} \\
& \begin{array}{rr}
-.44 & -.37 \\
.51 & . .42
\end{array} \\
& \begin{array}{lll}
-.35 & .18 & .14
\end{array} \\
& \begin{array}{ccc}
.04 & -.74 ! & -.46 \\
-.05 & .12 & -.45 a
\end{array} \\
& .45 \\
& -.68 b * .60 * \\
& -.25 \quad .65^{*} \\
& \begin{array}{ll}
-.03 & .30 \\
-.23 & .62
\end{array} \\
& \begin{array}{ll}
-.09 & -.13
\end{array} \\
& -.02 \\
& \begin{array}{r}
-.25 \\
.23
\end{array} \\
& -.62 \\
& \begin{array}{l}
-.16 \\
-.25
\end{array} \\
& .43 \\
& -.41 \\
& .06 \\
& \begin{array}{ll}
.16 & -.64^{*} \\
.52 & .25
\end{array} \\
& .30 \\
& \begin{array}{rr}
.01 & .47 \\
-.54 & .41 \\
& -.10
\end{array} \\
& -.43 \\
& \begin{array}{r}
.21 \\
-.08
\end{array} \\
& .01 \\
& \begin{array}{l}
.14 \\
.14
\end{array} \\
& \begin{array}{ll}
-.27 & -.14
\end{array} \\
& .00 \quad .42 \\
& -.86 b l \quad .28 \\
& \begin{array}{ll}
-.13 & .13 \\
. .28 & -.35
\end{array} \\
& \begin{array}{ll}
.28 & -.35
\end{array} \\
& .29-.75 ! \\
& \begin{array}{ll}
-.33 & .42 \\
.601 & -.741
\end{array} \\
& \begin{array}{ll}
.60 \mathrm{a} & -.741 \\
.44 & -.01
\end{array} \\
& -.48
\end{aligned}
$$

PRS-M

PRS-O

PRS-P

PRS-TO.

$$
\mathrm{K}
$$

MAS

ATTN

BI 1

BI 2

BI 3

B1 4

B1 5

B1 To.

a Difference between $\mathbf{r}^{\prime} \mathbf{s}$ (for A-L and A-NL groups) significant at .05 level

b Difference between $r^{\prime} s$ (for A-L and A-NL groups) significant at . Ol level

* r significantly different from zero at .05 level

1 r significantly different from zero at . Ol level 
TABLE 12. INTERCORRELATIONS FOR ALL

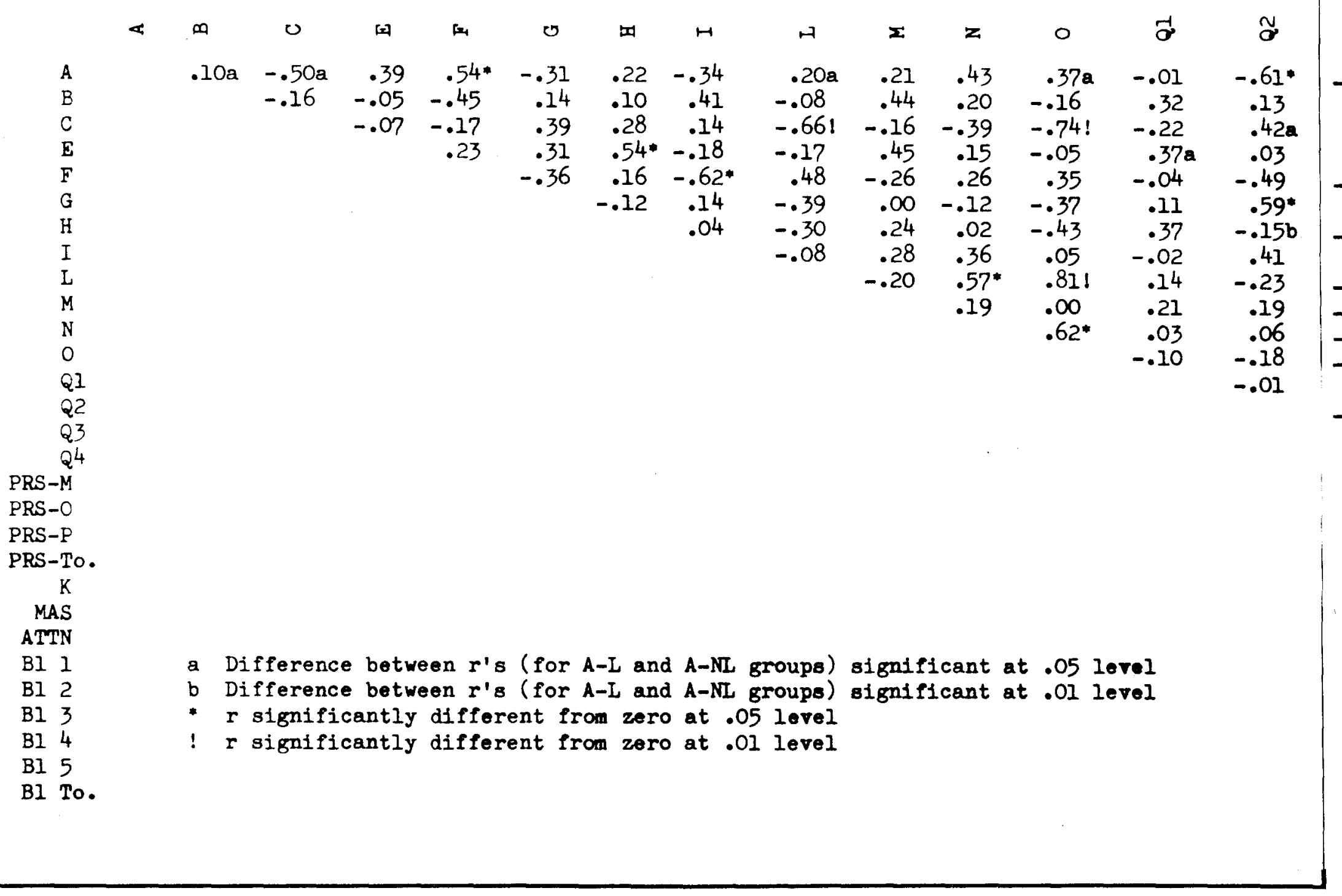


OR ALI

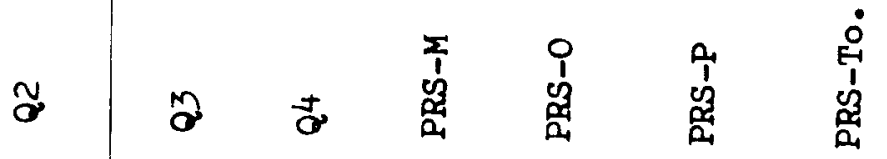

$-.61 *$

\begin{tabular}{l|ll}
.13 & -.13 & .16
\end{tabular}

$.42 a$

.03

$-.49$

$.59 *$

$-.15 b$

.41

$-.23$

.19

.06

$-.18$

$-.01$

\section{VARIABLES FOR A-NL GROUP $(N=15)$}

$$
\begin{aligned}
& \begin{array}{rrrrrrrrr}
-.13 & .16 & .29 a & -.19 & .31 a & .17 a & -.04 a & .15 a & -.03 \\
.26 & -.31 & . .15 & -.33 & .00 & -.12 & .39 a & -.12 & -.08 \\
.10 & -.34 & -.45 & -.07 a & -.791 & -.60 * & .47 & -.43 & -.15
\end{array} \\
& \begin{array}{lllllllllll}
.04 & .25 & .42 & -.07 a & -.79 ! & -.60 * & .47 & -.43 & -.15 & -.14 & .03
\end{array}
\end{aligned}
$$

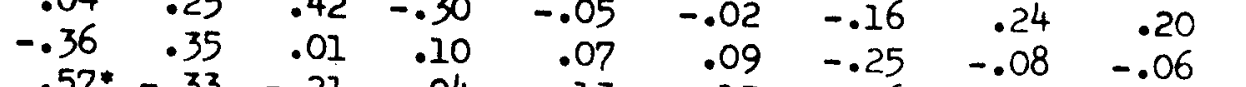

$$
\begin{aligned}
& \begin{array}{rrrrrrrrrrr}
.57 * & -.33 & -.01 & .04 & -.07 & -.09 & -.025 & -.08 & -.06 & .16 a & .44 \\
-.11 & -.07 & .05 & -.671 & -. .54 * & -.58 * & .16 & .07 & .07 & -.32 b & -.18 \\
.07 & -.42 & -.08 & -.12 & .06 & -.07 & -.04 & -.36 & -.027 & .19 & .04
\end{array}
\end{aligned}
$$

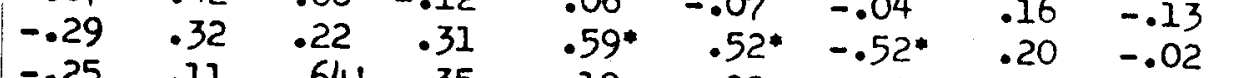

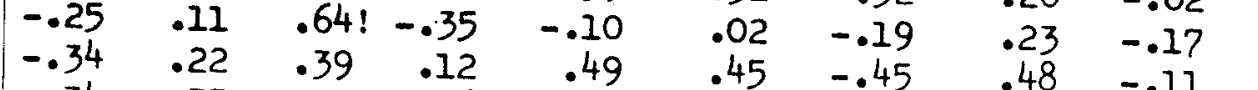

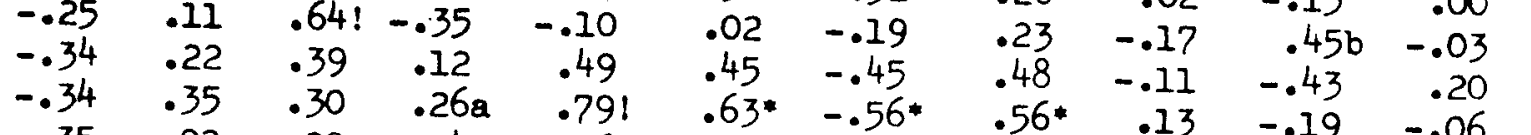

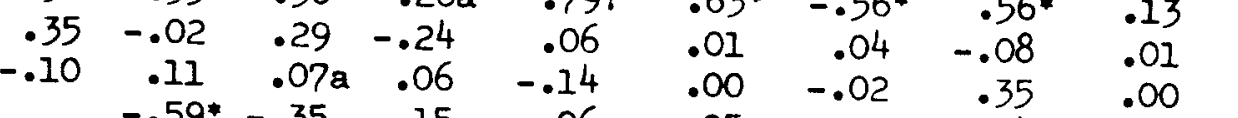

$$
\begin{aligned}
& -.59 *-.35 \\
& \begin{array}{lllll}
.06 & -.05 & .35 & -.24 & .00
\end{array} \\
& \begin{array}{llll}
.34 & .58 * & -.48 & .61^{*} \\
.28 & .58 * & -.40 & .52^{*}
\end{array} \\
& .42 \\
& .76 ! \\
& \begin{array}{ll}
-.40 & .52 * \\
-.45 & .34
\end{array} \\
& \begin{array}{ll}
-.45 & .34 \\
-.50 & .73 ! \\
-.63^{*} & .73 ! \\
-.54 *
\end{array} \\
& \begin{array}{llll}
. .04 a & .00 & -.031 a
\end{array} \\
& -.01 \quad .05 \\
& -.06 a-.20 \\
& \begin{array}{lllll}
.28 a & -.31 a & .02 & .18 & .01 \\
.09 & -.14 & .24 a & .28 a & .33
\end{array} \\
& \begin{array}{lllll}
.16 a & .16 & -.03 & -.44 & -.11
\end{array} \\
& -.38 \\
& -.12 \\
& \begin{array}{r}
.18 \\
-.14 \\
. .13
\end{array} \\
& \begin{array}{r}
.12 \\
-.28
\end{array} \\
& .53^{*} \\
& .23 \\
& .57 a^{*} \\
& .06 \\
& .21 \\
& .31
\end{aligned}
$$

$+$

in

미 $\dot{\circ}$

$\vec{m}$ 
These positive and negative correlations were reversed for the A-NL group. The correlations differed significantly for the two groups at the .05 level except for the following which differed at the .0I level: Factor $\mathrm{C}$, PRS Fersonal Inadequacy and $\mathrm{K}$.

Regarding the factor of Attention which differentiated between the Aware-Unaware groups, it also differentiated the A-I and A-NL groups in the same way. Attention correlated positively with Anxiety in the group which liked the reinforcement and negatively with the 1 Factor: q4 $(\underline{\underline{r}}=.76, p<.01)$; PRS-Object Anxiety $(\underline{\underline{x}}=.68, p<.05)$; PRS-Personal Inadequacy $(\underline{r}=.82, p<.01) ;$ TRS-Total $(\underline{r}=.68, p<.05) ;$ MAS $(\underline{x}=.60$, p .05; K $(\underline{x}=-.78, p<.01)$. These were 011 significantly different from the corresponding intercorrelations for A-NL group which were very low. These groups differed from each other on the anxiety variables at the .05 level and on the $K$ factor at the .01 level.

The large correlations between the anxiety-attention measures for the A-I group require further elaboration. A comparison of the corresponding intercorrelations for all subjects, including controls, indicated that generally there was a small positive correlation between anxiety and attention. The fact that the A-I subgroup had the highest mean Attention score $(M=12.50)$ although it was not significantly different from the $A-N I$ group $(M=11.27 ; \underline{t}=1.29$, n.s. $)$ was also a factor to be considered. Examination of the interview profiles for these two groups indicated that the reason given by the A-NI Group for disliking the reinforcoment was that use of the first person pronoun made them uncomfortable and selfconscious because they did not know what conforming would indicate about 
their personalities.

The fact that these Ss had very low anxiety scores on all

measures opens up the question of accounting for their uneasiness in the experimental situation. This same group also had scores indicating that they were more emotionally mature and more serious than the A-I group. While the A-I group had average scores on the emotional maturity factor $(\mathrm{N}-\mathrm{C})$ and the sober-gay factor $(\mathrm{PF}-\mathrm{F})$, it was above average on Factor $A-$ outgoing, sociaile. This difference was especially striking in view of the fact that the entire group of 120 js was below average on this factor. Regardins the Anxiety scores and theiv correlations with Blocks of Trials, in general a negative correlation existed between Blocks and all Anxiety measures for the group which liked the reinforcement. This was a resolution of opposing tendencies mentioned above where the correlations for the A group were generally positive and for the I group consistently negative. The subgroup A-I followed the tendency which appeared in the I group.

For the A-NL group, positive correlations existed, comparable to the NL group discussed above.

Thirteen of the possible 42 intercorrelations among the anxiety measures ( $P F-0, P F-24, P R S-M, P R S-0, P R S-P$, PRS-Total, MAS) were significantly different from each other for these two groups: 11 at the .05 level and 2 at the .01 level.

Another interesting feature of the Anxiety and $K$ scores for these groups was that for the A-I group all but one of the intercorrelations of the Anxiety measures were significantly different from zero whereas for 
the A-NL group only 15 of the 28 intercorrelations were significant. This seems noteworthy because in the A-U and I-NL groups intercorrelations were significant for each of the four groups. The fact that the subgroup A-NL should show such marked inconsistency in its intercorrelations was a further indication of the complex relationship of anxiety to other factors in the experimental situation.

Besides the anxiety scores the factor which distinguished the two groups most consistently in its correlation with Blocks was Factor M-Conventional (low score) vs. Imaginative (high score). This factor correlated positively with blocks in the A-NL group and negatively in the A-I group. These were significant for Blocks $I(p<.01), 4(p<.05)$ and $5(p<.01)$ and Total $(p<.01)$. It would seem that for the group which liked the reinforcement, conventionality was related to emitting the correct response. For the group which did not like the reinforcement, however, scores depicting imaginative tendencies were related to increase of the response.

\section{Unaware-Like and Unaware-Did Not like Groups}

It is, however, in the analysis of the data for the Unaware Group according to attitude that greater differences appear. It will be remembered that the $A-L$ and $A-N L$ groups differed only on the anxiety variable, the latter being less anxious. Also in the analysis of the entire experimental group according to attitude-I and NL Groups-significant differences were observed in 13 of the 23 variables. The present groups, U-I and U-NL, differed significantly on 12 of the 23 
variables, eleven of which were the same as the $I$ and NL groups. But there are several differences which are worth noting. (Table 13 contains the t-test data for these groups and Table 14 is a descriptive formulation of the differences.)

There are two varlables which differentiated the $L-N L$ groups which, however, were not significantly different in these groups when the Ss were unaware of the correct contingency. The failure to find a significant difference in Fersonality Factor E-conforming vs. independent--was that both groups, U-I and U-NL achieved higher scores, toward the independent end of the scale. This was the tendency which was evident in the I and NL groups.

For Personality Factor L--adaptable vs. Opinionated--the mean scores for the U-L and U-NI groups are similar to the $I$ and NL groups. A t score of 1.94 just failed to reach significance and in Flew of the smaller $N$ in these groups it may be conjectured that a difference could exist on this characteristic.

One additional variable which did not appear to differentiate the I and NL groups was significant at the .01 level for the U-I and U-NL groups. On Fersonality Factor N--forthright, "artless, natural" vs. shrewd, calculating, penetrating--each group moved toward the end of the scale according to the tendency indicated for the $N$ and $N$ groups in Table 7, page 31. The U-L group was revealed to be more forthright and "artless" and the U-NL group more shrewd and penetrating, although the latter's mean score was still within the average range of Cattell's norms. The low score of the U-I group on this factor accounts for the difference. 
TABLE 13

DIFFEREMCES BETWEEN URAWARE GROUPS ACCORDIMG TO ATTITUDE TOWARD REINPORCEMENT (U-L AID U-NL GROUPS)

\begin{tabular}{|c|c|c|c|c|c|}
\hline \multirow[b]{2}{*}{ Var1able } & \multicolumn{2}{|c|}{$U-I_{0}$} & \multicolumn{2}{|c|}{ U-NL } & \multirow[b]{2}{*}{ T-score } \\
\hline & Mean & $\mathbf{S D}$ & Mean & $S D$ & \\
\hline $\begin{array}{l}\text { PF-A } \\
\text { PF-B } \\
\text { PF-C } \\
\text { PF-B } \\
\text { PF-F } \\
\text { PF-G } \\
\text { PF-H } \\
\text { PF-I } \\
\text { PF-L } \\
\text { PF-M } \\
\text { PF-N } \\
\text { PF-O } \\
\text { PF-Q1 } \\
\text { PF-Q2 } \\
\text { PF-Q3 } \\
\text { PF-O4 } \\
\text { PRS-M } \\
\text { PRS-0 } \\
\text { PRS-P } \\
\text { PRS-Total } \\
\text { K } \\
\text { MAS } \\
\text { ATIN } \\
\text { Block } 1 \\
\text { BIock } 2 \\
\text { Block } 3 \\
\text { Block } 4 \\
\text { BIock } 5 \\
\text { Total Bl. }\end{array}$ & $\begin{array}{r}9.33 \\
9.83 \\
14.89 \\
8.22 \\
13.06 \\
16.61 \\
9.72 \\
13.72 \\
7.33 \\
13.78 \\
7.44 \\
15.28 \\
8.61 \\
10.56 \\
9.89 \\
14.28 \\
11.22 \\
7.78 \\
11.67 \\
30.67 \\
16.39 \\
17.33 \\
11.33 \\
6.22 \\
7.45 \\
7.06 \\
6.89 \\
7.56 \\
35.17\end{array}$ & $\begin{array}{l}3.38 \\
1.67 \\
3.36 \\
3.54 \\
5.40 \\
2.45 \\
5.09 \\
2.61 \\
2.79 \\
3.90 \\
1.99 \\
4.76 \\
2.56 \\
2.65 \\
3.03 \\
2.61 \\
4.22 \\
3.41 \\
5.03 \\
10.15 \\
4.85 \\
9.04 \\
1.92 \\
1.48 \\
2.72 \\
2.86 \\
4.07 \\
5.17 \\
13.87\end{array}$ & $\begin{array}{r}10.27 \\
9.47 \\
17.73 \\
10.67 \\
14.33 \\
17.93 \\
16.27 \\
14.00 \\
5.33 \\
11.33 \\
9.53 \\
8.60 \\
8.93 \\
8.80 \\
12.27 \\
11.80 \\
7.93 \\
4.13 \\
7.20 \\
19.27 \\
20.20 \\
7.53 \\
11.80 \\
5.40 \\
6.00 \\
6.33 \\
5.73 \\
5.93 \\
29.40\end{array}$ & $\begin{array}{l}3.77 \\
1.45 \\
3.83 \\
3.83 \\
3.93 \\
2.63 \\
4.85 \\
2.17 \\
2.93 \\
3.41 \\
2.21 \\
4.04 \\
2.87 \\
2.68 \\
3.27 \\
3.87 \\
3.64 \\
2.43 \\
3.90 \\
7.99 \\
3.13 \\
4.63 \\
2.25 \\
1.67 \\
2.83 \\
2.60 \\
2.59 \\
3.06 \\
10.33\end{array}$ & $\begin{array}{l}.72 \\
.64 \\
2.17 * \\
1.84 \\
.76 \\
1.43 \\
3.64 * * \\
.32 \\
1.94 \\
1.87 \\
2.75 * \\
4.20 * * \\
.33 \\
1.81 \\
2.09 * \\
2.05 * \\
2.33^{*} \\
3.48 * * \\
2.79 * \\
3.50 * * \\
2.63 * * \\
3.89 * * \\
.62 \\
1.44 \\
1.44 \\
.74 \\
.96 \\
1.09 \\
1.33\end{array}$ \\
\hline
\end{tabular}

Significance:

* .05 Level

* .01 leve1

***.001 level 
TABLE 14

DIFTEREACES BEIWIAEN U-L AND U-NL SUBJECTS ON PERSONALITY TRAITS

Description of Subjects

Factor Ss: U and Ilked reinforce. SB:U and ald not like relnforce. T

PF-C Av: emotional maturity

Ab.Av: emotlonal maturity

$2.17^{*}$

PF-H Below av: shy, restrained

$\mathrm{Ab} . \mathrm{Av}$ : venturesome, socially 3.64*w: bold

$\begin{array}{ll}\text { PF-N } & \text { Av: forthright, "natural" } \\ \text { FP-0 } & \begin{array}{l}\text { Ab. av: apprehensive, } \\ \text { worrying }\end{array} \\ P F-Q_{3} & \text { Av: casual, controlled }\end{array}$

PF-Q4 Av: tense, fretful

PRS-M AV: motor tension

RRS-0 Av: object tension

PRS-P Av: personal inadequacy

PRS-Tot. Av: anxiety

MAS Av: anxiety

K (MMP) Av: defensiveness
Av: shrewd, penetrating

$2.75^{* *}$

Below av: placid, seleassured

Ab.Av: more controlled, socially preclse

Relaxed, tranquil

$2.05^{*}$

Less tension

2.33*

Less tension

$3.48 *$

Less feeling of personal inadequacy

Less anxiety $3.50 * * *$

Less andiety $3.89 * * * *$

Ab.Av: defensiveness
$2.79^{* *}$ $2.63^{* *}$

Significance:

* .05 level

* .01 level

***.001 level 
Another important difference was revealed by further study of

Personality Factor-H--shy vs. bold--wich differentiated the I and NL groups at the .05 level. This factor differentiated the $\mathrm{U}-\mathrm{L}$ and $\mathrm{U}-\mathrm{NL}$ groups at the .001 level. The U-I group was below average on this factor, that is, more shy and the U-NI group, above arerage, that is, more bold and venturesome. Unawareness seemed to be the exucial factor in this difference. When the subjects were aware ( $A-I$ and $A-N L$ groups) no differences appeared in this factor $($ Mean $(A-L)=12.00 ;$ Hean $(A-N L)=11.47 ; t=.25$ n.s.). With attitude held constant, NL-A and NL-U, a significant difference was also revealed $($ Mean $(N L-A)=11.47$ and Mean $(N L-U)=16.27 ; \underline{t}=2.57, p<.05)$. The analysis of the intercorrelation data (Tables 15 and 16 rerealed significant interactions between $P F-G$ and other variables, a tendency noted earlier in the discussion of the A-U groups. The trend evident there wa more explicit when the unaware group was analyzed according to attitude. In the U-I Group, Factor G--expedient vs. conscientious-correlated negatively with PF-O $(\underline{\underline{x}}=-.55), \mathrm{PF}-\mathrm{Q2}(\underline{\underline{x}}=-.78), \mathrm{PRS}-0$ $(\underline{x}=-.71)$ and PRS-Total $(\underline{x}=-.61)$; these were significant at the .01 level. In the U-NL group, PF-G correlated positively with $P F-O(I=.34)$, Q2 $(\underline{I}=.29)$ and PRS-Total $(\underline{x}=.06)$, and negatively with PRS-0 $(\underline{\underline{x}}=-.03)$. These $\underline{I}^{\prime} \mathrm{s}$ were significantly different from each other for the two groups. 
TABLE 15. INTERCORRETATIONS FOR ALL

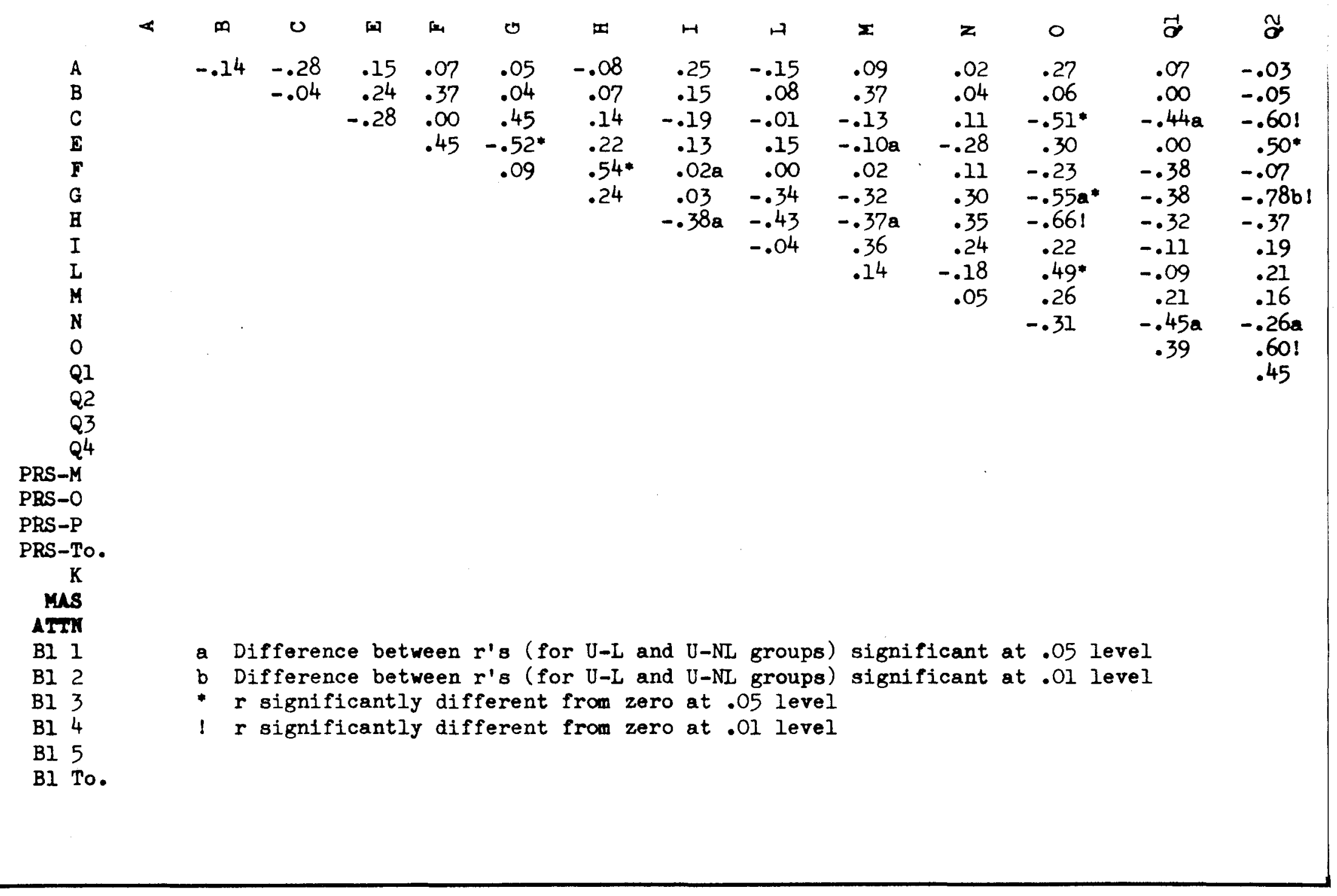


FOR ALL VARIABLES FOR U-L GROUP $(N=18)$

\begin{tabular}{|c|c|c|c|c|c|c|c|c|c|c|c|c|c|c|c|}
\hline$\tilde{\alpha}$ & $\stackrel{m}{a}$ & वै & $\begin{array}{l}\Sigma_{1} \\
\dot{g} \\
\mathfrak{\alpha}_{a}\end{array}$ & 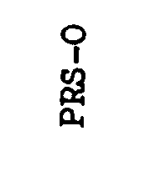 & 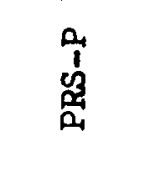 & 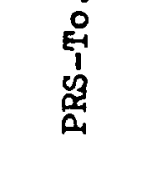 & 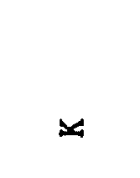 & $\frac{\text { 年 }}{2}$ & 圛 & $\vec{n}$ & $\begin{array}{l}\sim \\
\vec{D}\end{array}$ & $\begin{array}{l}m \\
\vec{m}\end{array}$ & $\begin{array}{l}\vec{a} \\
\vec{\omega}\end{array}$ & $\begin{array}{l}n \\
m-1\end{array}$ & $\begin{array}{l}\dot{0} \\
\dot{E} \\
-1\end{array}$ \\
\hline $\begin{array}{l}-.03 \\
-.05 \\
-.60 ! \\
.50 \\
-.07 \\
-.78 b ! \\
-.37 \\
.19 \\
.21 \\
.16 \\
-.26 a \\
.60 ! \\
.45\end{array}$ & $\begin{array}{l}-.20 \\
-. .38 a \\
.43 \\
-.13 \\
-.09 \\
-.08 \\
.09 \\
-.48 \\
.30 \\
-.15 \\
-.25 \\
-.17 \\
.11 \\
-.07\end{array}$ & $\begin{array}{r}-.01 \\
-.07 \\
-.030 \\
-.02 \\
-.04 \\
-.25 \\
-.24 \\
-.04 \\
.25 \\
.38 \\
-.09 \\
.42 \\
.27 \\
.33 \\
.07\end{array}$ & $\begin{array}{r}.09 \\
.22 \\
-.36 \\
.03 \\
.29 \\
-.16 \\
-.19 \\
-.12 \\
.34 \\
.05 \\
-.13 \\
.16 \\
.23 \\
.27 \\
-.05 \\
.09\end{array}$ & $\begin{array}{c}-.04 \\
.10 \\
-.51 * \\
.19 \\
-.29 \\
-.71 a ! \\
-.70 ! \\
.12 \\
.49 * \\
.48 * \\
-.54 * \\
.76 ! \\
.51 b ! \\
.71 ! \\
.03 \\
.40 \\
.34\end{array}$ & $\begin{array}{l}.22 \\
.05 \\
-. .70 ! \\
.14 \\
-.06 a \\
-.61 ! \\
-.60 ! \\
.41 \\
.30 \\
.50 * \\
.02 \\
.77 ! \\
.42 \\
.71 ! \\
-.40 \\
.45 \\
.32 \\
.75 !\end{array}$ & $\begin{array}{c}.13 \\
.14 \\
-.67 ! \\
.14 \\
-.11 \\
-.61 a ! \\
-.61 ! \\
.19 \\
.45 \\
.43 \\
-.23 \\
.70 ! \\
.50 a \\
.70 ! \\
-.21 \\
.39 \\
.68 ! \\
.84 ! \\
.88 !\end{array}$ & $\begin{array}{r}.17 \\
-.30 \\
.43 \\
-.15 \\
-.25 \\
.34 \\
. .34 \\
-.16 \\
-. .68 ! \\
-.36 \\
-.03 \\
-.46 \\
-.03 \\
-.38 \\
.20 \\
-.46 \\
-.63 ! \\
-.52 \\
-.59 ! \\
-.73 !\end{array}$ & $\begin{array}{c}.31 \\
.08 \\
-.57^{*} \\
.03 \\
.08 \\
-.32 \\
-.45 \\
.33 \\
.40 \\
.34 \\
.18 \\
.61 ! \\
.20 \\
.42 \\
-.39 \\
.41 \\
.641 \\
.47 \\
.80 ! \\
.821 \\
-.77 !\end{array}$ & $\begin{array}{r}.31 \\
.13 \\
-.10 \\
.02 \\
-.28 \\
-.15 \\
-.29 \\
.10 \\
.28 \\
.36 \\
-.06 \\
.26 \\
.11 \\
-.05 \\
-.23 \\
-.10 \\
-.14 \\
.21 \\
.27 \\
.14 \\
-.05 \\
.09\end{array}$ & $\begin{array}{r}-.18 \\
-. .33 \\
-.02 \\
.08 \\
.07 \\
.08 \\
.36 \\
-.02 \\
-.06 \\
-.02 \\
.18 \\
-.22 \\
-.25 \\
-.19 \\
.08 \\
-.08 \\
-.41 \\
-.30 \\
-.27 \\
-.41 \\
.07 \\
-.028 \\
.06\end{array}$ & $\begin{array}{c}-. .27 \\
-.43 \\
. .19 \\
-. .34 \\
-.48 \\
. .23 \\
-.11 \\
.02 \\
-.35 \\
-.11 \\
-.02 \\
-.32 \\
-.02 \\
.02 \\
.17 \\
-.13 \\
-.42 \\
-.06 \\
-.16 \\
-.27 \\
. .42 \\
-.50 a^{*} \\
-.08 \\
.02\end{array}$ & $\begin{array}{c}-.21 \\
-.23 \\
.46 a \\
.05 \\
-.15 \\
.17 \\
.23 \\
.02 \\
-.29 \\
-.10 \\
.02 \\
-.51 b^{*} \\
-.22 \\
-.16 \\
.32 \\
-.28 \\
-.56 * \\
-.32 \\
-.49 * \\
-.59 ! \\
.51 * \\
-.73 a ! \\
.00 \\
.48 * \\
.69 !\end{array}$ & $\begin{array}{r}-.01 \\
-.29 \\
.07 \\
.07 \\
-.04 \\
.15 \\
.16 \\
.14 \\
-.33 \\
-.06 \\
.28 \\
-.30 \\
-.22 \\
.06 \\
-.02 \\
-.08 \\
-. .33 \\
-.28 \\
-.12 \\
-.29 \\
.21 \\
-.28 \\
-.02 \\
.51 \\
.67 ! \\
.78 !\end{array}$ & $\begin{array}{c}.13 \\
-.19 \\
.17 \\
.03 \\
.12 \\
.36 \\
.20 \\
.32 \\
-.32 \\
-.12 \\
.44 \\
-.37 \\
-.49 * \\
-.05 \\
-.07 \\
-.10 \\
-.29 \\
-.48 a^{*} \\
-.22 \\
-.39 \\
.23 \\
-.25 \\
-.15 \\
.33 \\
. .51 \\
. .67 ! \\
. .87 !\end{array}$ & $\begin{array}{r}-.07 \\
-. .33 \\
.21 \\
-.02 \\
-.09 \\
.26 \\
.18 \\
.16 \\
-.35 \\
-.13 \\
.26 \\
-.42 a \\
-.33 \\
-.05 \\
.07 \\
-. .15 \\
-.45 \\
-. .37 \\
-.28 \\
-.45 \\
. .34 \\
-.46 \\
-.08 \\
. .52 \\
.751 \\
.87 ! \\
.961 \\
.901\end{array}$ \\
\hline
\end{tabular}


TABLE 16. INTERCORREIAATIONS FOR ALL

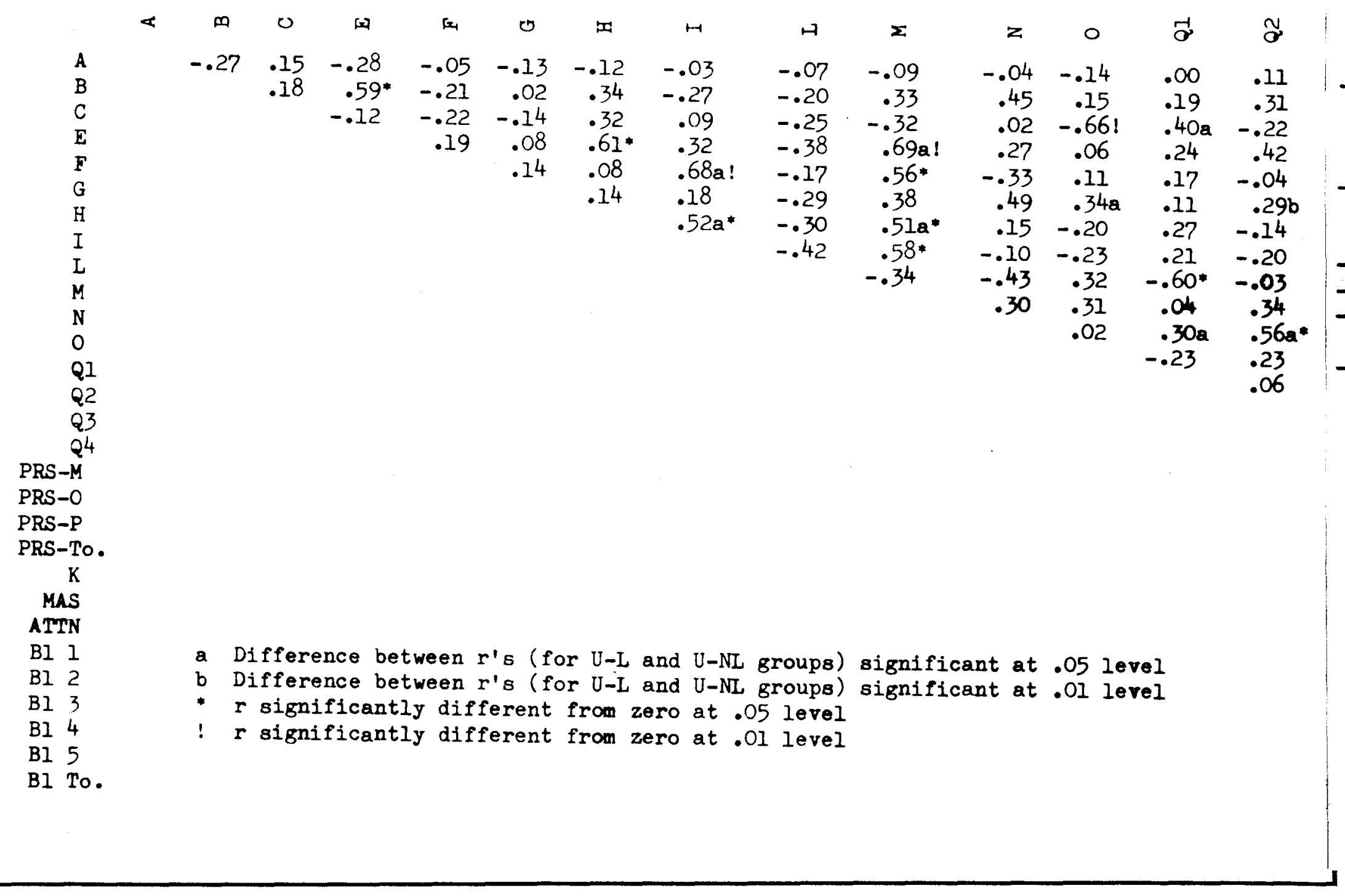


FOR ALL VARIABLES FOR U-NL GROUP (N = 15)

\begin{tabular}{|c|c|c|c|c|c|c|c|c|c|c|c|c|c|c|c|}
\hline$\widetilde{\sigma}$ & $\stackrel{a}{a}$ & む゙ & 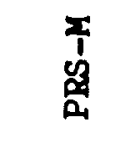 & 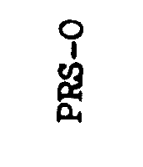 & 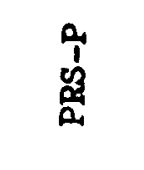 & 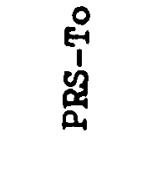 & 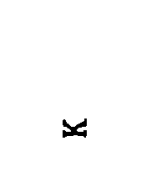 & $\frac{n}{2}$ & 总 & $\begin{array}{l}\vec{H} \\
\vec{m}\end{array}$ & $\begin{array}{l}\sim \\
\vec{D}\end{array}$ & $\begin{array}{l}m \\
m \\
m\end{array}$ & $\begin{array}{l}\vec{y} \\
\text { an }\end{array}$ & nn & $\begin{array}{l}\text { 우 } \\
\text { - }\end{array}$ \\
\hline $\begin{array}{r}.11 \\
.31 \\
-.22 \\
.42 \\
-.04 \\
.29 \mathrm{~b} \\
-.14 \\
-.20 \\
-.03 \\
.34 \\
.56 \mathrm{a} \\
.23 \\
.06\end{array}$ & $\begin{array}{c}-.38 \\
.36 a \\
.34 \\
. .22 \\
-.13 \\
.30 \\
.04 \\
-.22 \\
-.13 \\
-.03 \\
.29 \\
-.09 \\
.33 \\
.43\end{array}$ & $\begin{array}{c}-.52 \\
-.08 \\
-.00 ! \\
.12 \\
.29 \\
-.16 \\
-.06 \\
.08 \\
.45 \\
.20 \\
-.28 \\
.54 * \\
-.25 \\
-.17 \\
-.34\end{array}$ & $\begin{array}{r}-.11 \\
-.23 \\
-.48 \\
.12 \\
.15 \\
.21 \\
-.12 \\
.35 \\
.01 \\
.42 \\
.28 \\
.42 \\
-.16 \\
.31 \\
-.16 \\
.37\end{array}$ & $\begin{array}{l}-.10 \\
-.14 \\
-.36 \\
.00 \\
.23 \\
-.03 a \\
-.13 \\
-.05 \\
.64 ! \\
.16 \\
-.32 \\
.46 \\
-.40 b \\
. .24 \\
-.03 \\
.39 \\
.32\end{array}$ & $\begin{array}{c}-.12 \\
.03 \\
-.49 \\
.13 \\
.47 a \\
-.03 \\
-.32 \\
.09 \\
.24 \\
.29 \\
-.25 \\
.58 \\
-.11 \\
.22 \\
-.20 \\
.48 \\
.41 \\
.66 !\end{array}$ & $\begin{array}{c}-.14 \\
-.14 \\
-.57^{*} \\
.12 \\
.37 \\
.06 a \\
-.25 \\
.19 \\
.31 \\
.38 \\
-.09 \\
.61 * \\
-.26 a \\
.32 \\
-.19 \\
.52 * \\
.75 ! \\
.77 ! \\
.87 !\end{array}$ & $\begin{array}{c}.43 \\
-.22 \\
.41 \\
-.52 \\
-.34 \\
-.02 \\
-.14 \\
-.27 \\
-.28 \\
-.58 \\
.12 \\
-.41 \\
.41 \\
-.30 \\
.03 \\
-.50 \\
-.49 \\
-.68 ! \\
-.67 ! \\
-.76 !\end{array}$ & $\begin{array}{r}-.12 \\
-.06 \\
-.41 \\
.08 \\
.18 \\
-.04 \\
-.033 \\
.11 \\
.26 \\
.19 \\
.01 \\
.47 \\
-.13 \\
.34 \\
-.18 \\
.43 \\
.72 ! \\
.55 * \\
.84 ! \\
.90 ! \\
-.63 *\end{array}$ & $\begin{array}{c}-.39 \\
. .61 \\
-.11 \\
.18 \\
-.06 \\
.37 \\
-.01 \\
-.17 \\
-.10 \\
.28 \\
. .33 \\
.34 \\
-.18 \\
.15 \\
.33 \\
.08 \\
-.02 \\
-.29 \\
-.02 \\
-.11 \\
-.15 \\
-.05\end{array}$ & $\begin{array}{r}.18 \\
-.12 \\
.32 \\
.05 \\
-.40 \\
-.06 \\
.03 \\
-.10 \\
-.03 \\
-.46 \\
-.17 \\
-.25 \\
.13 \\
.03 \\
. .14 \\
-. .34 \\
-.20 \\
-.14 \\
-.11 \\
-.19 \\
.18 \\
.05 \\
-.23\end{array}$ & $\begin{array}{r}.14 \\
.17 \\
-.20 \\
.11 \\
-.24 \\
.27 \\
-.21 \\
-.15 \\
-.28 \\
.01 \\
.14 \\
.40 \\
-.08 \\
.09 \\
-.23 \\
-.10 \\
.19 \\
-.17 \\
.26 \\
.16 \\
-.06 \\
.26 a \\
.23 \\
.36\end{array}$ & $\begin{array}{c}.12 \\
-.04 \\
-.27 a \\
-.18 \\
-.28 \\
. .33 \\
-.25 \\
-.27 \\
.09 \\
-.10 \\
-.01 \\
.042 b \\
-.46 \\
-.05 \\
-.33 \\
.00 \\
.08 \\
.00 \\
.02 \\
.04 \\
-.03 \\
-.02 a \\
.21 \\
.10 \\
.76\end{array}$ & $\begin{array}{r}.49 \\
.23 \\
-.16 \\
.05 \\
-.47 \\
.07 \\
-.15 \\
-.47 \\
.00 \\
-.09 \\
.12 \\
.37 \\
-.21 \\
.22 \\
-.12 \\
-.23 \\
-.08 \\
-.021 \\
-.11 \\
-.15 \\
.19 \\
-.09 \\
.25 \\
.34 \\
.69 ! \\
.65 !\end{array}$ & $\begin{array}{r}.18 \\
.18 \\
-.03 \\
.33 \\
-.18 \\
.10 \\
.03 \\
-.08 \\
-.02 \\
.08 \\
-.11 \\
.22 \\
-.26 \\
.24 \\
-.06 \\
-.22 \\
.06 \\
.28 \\
.31 \\
.26 \\
-.39 \\
.25 \\
-.05 \\
.54 * \\
.72 ! \\
.58 * \\
.56 *\end{array}$ & $\begin{array}{r}.27 \\
.12 \\
-.12 \\
.10 \\
-.38 \\
.19 \\
-.15 \\
-.26 \\
-.07 \\
-.10 \\
.00 \\
.330 \\
-. .25 \\
.18 \\
-.17 \\
-.21 \\
.04 \\
-.04 \\
.12 \\
.06 \\
-.06 \\
.12 \\
.12 \\
.53 * \\
.91 ! \\
.80 ! \\
.82 ! \\
.86 !\end{array}$ \\
\hline
\end{tabular}




\section{CHAPTER V}

\section{CONCLUSIONS}

\section{Conditioning Data}

In accordance with expectations there was no significant difference in conditioning scores anong the experimental group, taken as a whole, and the two control groups. There are too many factors recognized in the experimental situation, some of which were discussed in the Introduction and the Review of the Literature, to allow the experimenter to predict a difference based solely on patterned reinforcement. Warly experimenters who found differences often did so by eliminating aware $\underline{S}$ or by preselecting $\underline{S}$ according to some differentiating characteristic such as anxiety. More will be said about this later.

Regarding the control groups, an earlier study (Babladel1s, 1961) had discovered use of random reinforcement to be a better control than no reinforcement. With no reinforcement Ss showed a gradual decrease in the critical response. In the present experiment this did not occur. The randomly-reinforced control group showed the same general trend as the experimental groups--a decline in response on the fourth block; whereas the non-reinforced control group continued to show an increase.

The explanation for this may be that reinforcement of any kdnd tended to meke the Ss used in this experiment self-conscious. These Ss are 
at a point in their religious formation where they are encouraged to avold self-reference in their conversation as much as possible. The $\underline{S}$ in the randomly-reinforced control group may have arolded using the first person pronoun simply because the reinforcement drew attention to them even though the first person pronouns were not specifically reinforced. In the nonreinforced group no attention was directed to the use of the pronouns. Contrary to predictions the variable of awareness did not yield significant differences in conditioning behavior for $\underline{5}$ who were aware $(N=27)$ and $\underline{S}$ who were unaware $(N=33)$ according to the interview schedule. Being aware of the correct contingency alone is no guarantee that

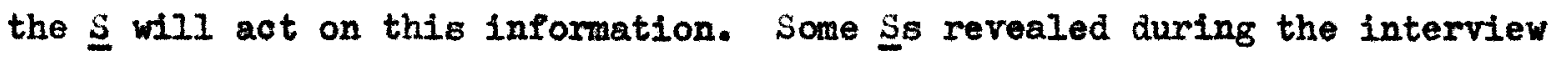
that they "tested" the experimenter to determine whether or not they had correctly interpreted the response contingency and having satisfied themselves that they had, they returned to what they considered a random use of all the pronouns. They saw no reason to emit the "correct" pronoun primarily because they did not know what such conformity would reveal about themselves. For some of the Ss use of "I" and "We" was suggestive of egocentricity and they decided to avold overusing these pronouns.

In spite of this decision by the aware $\underline{5}$, however, attitude was an influential factor in their behavior. If they liked the reinforcement and found it pleasant, they increased the use of the critical response. This was borne out by the significant results in conditioning between the A-L and A-NL groups.

It was rather surprising, however, to find significant results in conditioning data solely on the basis of attitude--L and NL groups. Eren 
though the Is were unaware of the oarrect contingenoy they increased the muber of "I" and "We" pronouns if they found the reinforcement pleasant. This was the unnistakable trend in the U-I, and U-NL groups even though the resulta did not reach tatistical signiflcance. Ferhaps if $3 \mathrm{~s}$ liked the reinforcement and felt wore at ease in the experimental situation because of this, they may have turned more readily to a use of first person statenents. Fhs, therefore, could be an artifact of the experinental aituation, $i_{0} \theta$. use of "I" and "We" evaking this personal response, were it not for the fact that the aware Ss who deolded not to use the critical pronouns, in splte of this deciolon, inereased their responses if they liked the reinforcement. It is, therefore, possible to suggest that positive attitude toward reinforcent in an experimental situstion such as this is influential in conditioning.

\section{Personal1tx Characteristics}

Because of the results of the conditioning process, the differences In personality characteriatica between the various groups proved to be highly provocative but extremely complex.

The factor of anxiety figured prominently in all subgroups divided according to ttitude toward reinforcenent: I-NL; $A-I-A-N L ; U-I-U-N L$. Sven though there were no such differences in mean scores for anxioty for the A-U group, there were Indications fron the intercorrelations of this factor with others that it differentiated the two gxoups.

The anxiety soores of the A group (Iow average for both $A$ and $V$ groups) correlated negatively (stgnificant at .05 or .01 levels) with 
Factor G--conscientious and mule-bound. No such significant correlations were found in the $U$ group. Since $P F-G$ is the only factor which differentiated these two groups, it would be unwise to place too much emphasis upon it but in confunction with the differences in anxiety noted between the other subgroups the intercorrelational differences in the A-U groups may serve as confimation of the complex role of anxiety in this experimental situation.

In the groups in which differences in anxiety played a major roleI-NL; A-L-A-NL; and U-I-D-NL--some explanation may be attempted. Low anxiety was associated with the groups which did not like the reinforcement, regardless of whether they were aware or not. An average amount of anxiety characterized the groups which liked the reinforcement. In previous experiments it had been hypothesized that anxiety was characteristic of those who condition. As noted in the review of the literature this has been as often not corroborated as corroborated. An explanation for these conflicting findings alght be found in the evidence from this experiment that the $\underline{S}$ who conditioned had average scores on anxiety, not high scores. If the previous investigators dichotomized their groups into low and high anxious Ss, perhaps the latter did not condition because of high anxiety. If the experimenter adopted the procedure of correlating conditioning scores with anxiety scores which were normally distributed, the high anxiety scores may also have disturbed whatever correlation trends may have existed in the low and medium ranges.

Another avenue of exploration to explain the finding that low anxious $\underline{S}_{s}$ did not like the reinforcement and did not condition might be to 
conslder andety in terms of reactivity. Low anxious persons are low reactors who keep themseltres calm by exercising control over the enviroment. In the present experimental situation such $\mathrm{Ss}$ might be less favorably dioposed toward reinforcement administered by the experimenter. But perhaps the main reason for the difference between the results of this experiment and previous ones is the fact that the $\underline{S} s$ in the present experiment were divided according to attitude alone and according to attitude and awareness. Along these dimensions several other personality factors differentiated the groups in addition to anxiety. Anxiety alone may not be the differentiating factor.

In analyzing Ss according to attitude toward the reinforcement, it was discovered that $\underline{S} s$ who did not like the reinforcenent and, therefore, did not condition, manifested personality characteristics quite deferent from those who did condition. Those who did not condition may be described as above average in emotional maturity, independence; they are socially bold, venturesome, somewhat shrewd and penetrating, relaxed, self-assured but at the same time socially preclse. In addition, Ss who did not like the reinforcement and were also unaware tended to be more venturesone and socially bold and in this same unaware group those who liked the reinforcement tended to be very shy and timid.

Some comparisons between these findings and other studies may be ventured. It is not possible to make direct comparisons because no other study has empioyed the same instruments to assess personality characteristics. Most have used HPPS. If emotional maturity and independence way be considered analogous to autonomy and self-esteem, the present findings that 
these were negatively related to conditioning would support the findings of Gelfand (1962) and Vestre (1962) and also the work of Marlowe (1963) and Crowne and Strickland (1961) who investigated need for approval.

The fact that other investigators found conflicting evidence when investigating isolated variables and the fact that in the present experiment several personality characteristics and complex interactions differentiated conditionable groups may indicate that in investigating attitude and the intricate relationship of personality variables which correspond to it we may learn a great deal about the effect of verbal reinforcements in a conditioning situation. 
CHAPTSR VI

\section{SUMARY}

In a verbal conditioning experiment $120 \mathrm{Ss}$, who had previously teken Cattell's 16 PF Questionnaire, Nicolay-Walker PRS, and WAIS Attention Test, were divided into an experimental and two control groups. Ss in the experimental group were reinforced with "mm hrm" for the entasion of "In and me" pronouns. For analysis the experimental group mes aubdirlded on the besis of awareness of the correct contingency and attitude toward the reinforcement.

Conditioning scores analyzed according to Edwards Trend Analysis indicated that the group $(\mathrm{N}=30)$ which liked the reinforcement conditioned $(p<.01)$ regardless of awareness or unawareness of the correct contingency.

The analysis of personality characteristics revealed that the factor of anxiety, which bore a complex relationship to other variables distinctive for each group, differentiated those $S$ s who did not like the reinforcenent from those who did. The former were characterized by less than average anxlety and positive correlations of this measure with conditioning ecores; the opposite trend held for Ss who liked the reinforcement.

It was suggested that in future research attitude toward reinforcement and latercorrelations of personality characteristics be studied in ordor to define more precisely the complex role of anxiety in verbal conditioning experinents. 
REEERENCES

Babladelis, Georgia. Personality and verbal conditioning effects. J. abnorm. soc, Psychol., 1961, 62, 41-43.

Caims, R. B. and Lews, M. Dependency and the reinforcement value of a vorbal stimulus. J. consult. Psychol, 1962, 26, 1-8.

Cattell, R. B. and Eber, H. W. Handbook for the sixteen personality factor questionnaire. Champaign, III.: Institute for personality and ability testing, 1964.

Cohen, B. D., Kalish, H. I., Thurston, J. R., and Cohen, S. Experimental mantpulation of verbal behavior. J. exp. Psychol., 1954, 47, 106-110.

Crowne, D. P. and Striakland, Bonnie R. The conditioning of rerbal beharior as a function of the need for social approval. J. abnorm. soc. Psychol., $1961,63,395-401$.

Dulaney, D. L. Hypotheses and habits in verbal operant conditioning. J. abnorm. soc. Psychol., 1961, 63, 251-263.

Edwards, A. I. Statistical methods for the behavioral sciences. New Yorks Rinehart and Co., Inc., 1954.

Ekman, F., Krasner, L., and UIImann, L. Interaction of set and awareness as determinants of response to rerbal conditioning. J. abnorm. soc. Psychol., $1963,66,387-389$.

Epstein, R. Need for approval and the conditioning of verbal hostility in asthmatic chlldren. J. abnorm. soc. Psychol., 1964, 69, 105-109.

Briksen, C. W. (Ed) Behavior and Awareness: A symposium of research and Interpretation. Durham, N. C.: Duke University Press, 1962.

Friksen, C. W., Kuethe, J. W., and Sullivan, D. Some personality correlates of learning without verbal awareness. J. Pers., 1958, 26, 216-228.

Eysenck, H. J. Fersonality and rerbal conditioning. Esychol. Rep., 1959, 5. 570 . 
Farber, I. E. The things people say to themselves. Amer. Psychologiat, $1963,18,185-197$.

Gelfand, Donna M. The influence of self-esteem on rate of verbal conditioning and social matching behavior. J. abnorm. soc. Psychol., 1962, 65, 259-265.

Greenspoon, J. The reinforcement effect of two spoken sounds on the frequency of two responses. Amer. J. Psychol... 1955, 68, 409-416.

Greenspoon, J. Verbal conditioning and clinical psychology. In A. J. Bachrach, (Ed). Experimental foundations of clinical psychology. New York: Basic Books, 1962.

Haas, K. Verbal conditioning of affective responses. J. gen. Psychol. 1962, 67, 319-322.

Hathaway, S. R. and McKinley, J. C. Manual for the MMPI. New York: Psychological Corporation, 1951.

Hetrick, W. R. and Haas, K. Some personality correlates of verbal conditioning. J. Parchol., 1962, 53, 409-415.

Kimble, G. Classical conditioning and the problem of awareness. In C. W. Eriksen, (Ed.). Behavior and Awareness. Duke University Press, 1962.

Kirman, W. J. The relationship between learning, with and without awareness, to personality needs. Unpublished Ph.D. Dissertation, Columbia University, 1958.

Krasner, I. Studies of the conditioning of verbal behavior. Psychol. Bu11.. 1958, 15, 248-171.

Krasner, L., UIImann, L. F., Weiss, R. L., and Collins, Beverly J. Responsivity to verbal conditioning as a function of three different examiners. J. clin. Psychol., 1961, 17, 411-415.

Krasner, I. and UIImann, L. Variables affecting report of awareness in verbal conditioning. J. Psychol., 1963, 56, 193-202.

Levin, S. M. Iffects of awareness in verbal conditioning. J. exp. Esychol.. 1961, 61, 67-76.

Marlowe, D. Need for social approval and the operant conditioning of meaningful verbal behavior. J. consult. Psychol., 1962, 26, 79-83.

Matarazzo, J. D., Saslow, G., and Pareis, E. N. Verbal conditioning of two response classes: Some methodical considerations. J. abnorm. soc. Psychol., 1960, 61, 190-206. 
McDonnell, Carol R., and Inglis, J. Verbal conditioning and personality. Esychol. Rep., 1962, 10, 374 .

Rogers, J. M. Operant conditioning in a quasi-therapy condition. J. abnorm. soc. Isychol., 1960, 60, 247-252.

Salzinger, K. Experimental manipulation of verbal behavior: A review. J. sen. Psychol., 1959, 61, 65-94.

Sapolsky, A. Effect of interpersonal relationships upon verbol conditioning. J. abnorm. soc. Psychol., 1960, 60, 241-246.

Sarason, I. G. Interrelationships among individual difference variables, behavior in psychotherapy, and verbal conditioning. J. abnorm. soc. Psychol., 1958, 56, 339-344.

Sarason, I. G. and Minard, J. Interrelationships among subject, experimenter, and situational variables. J. abnorm. soc. Psychol., 1963. 67. $87-91$.

Skinner, B. F. Verbal behavior. New York: Appleton-Century-Crofts, Inc., 1957.

Slechta, Joan, Gwynn, $W_{.}$, and Feoples, C. Verbal conditioning of schizophrentes and normals in a situation resembling psychotherapy. J. consult. Psychol., 1963, 27, 223-227.

Spielberger, $C$. D. The role of awareness in verbal conditioning. J. Eers., 1962, 308, 73-101.

Spielberger, C. D., Berger, A., and Howard, Kay. Conditioning of verbal behavior as a function of awareness, need for social approval, and motivation to receive reinforcement. J. abnorm. soc. Fsychol., 1963, 67. $241-245$.

Spielberger, C. D. and DeNike, L. D. Operant conditioning of plural nouns: A fallure to replicate the Greenspoon effect. Esychol. Rep., 1962, II. 355-366.

Spielberger, C. D., Levin, S., and Shepard, Mary. The effects of awareness and attitude toward the reinforcement on the operant conditioning of verbal behavior. J. Pers., 1962, 30, 106-121.

Taffel, C. Anxiety and the conditioning of verbal behavior. J. abnorm. soc. Psychol., 1955, 21, 496-501.

Taylor, Janet A. A personality scale of manifest anxiety. J. abnorm. soc. Psychol., 1953, 48, 285-290. 
Vestre, N. Relationship between verbal conditionability and the Edwards Personal Preference Schedule. J. clin. Psychol., 1962, 18, 513-515.

Walker, R. i. and Nicolay, R. C. A Reexamination of anxiety: The Nicolay-Walker personal reaction achedule. Loyola Unjversity, Chicago: Unpublished manuscript, 1963.

Wechsler, D. The moasurement and appraisal of adult intelligence. Baltimore: Williams and Wilkins, 1958.

Weinstein, $W . K$. and Lawson, R. The effect of experimentally-induced awareness upon performance in free-operant verbal conditioning and on subsequent tests of awareness. J. Psychol., 1963, 26, 203-211.

Williams, Juanita H. Conditioning of verbalization: A review. Fsychol. Buzl.., 1964, 62, 383-393.

Winfree, P. and Meyer, M. Sociability and the conditioning of pronouns "I" and "We." Psychol. Rep., 1963, 13, 781-782. 
1. Froted

2. read

3. achievad

4. forgave

5. hinted

6. zecoired

7. demended

8. diecerded

9. agreed

10. eang

11. rode

12. $581 d$

13. spotse

14. talked

15. washed

16. quit

17. painted

18. pulled

19. planted

20. played

21. pourred

22. predicted

23. valted

21. showed

25. N10r

26. followed

27. forgot

28. recognised

29. rencebsend

15. Wad

31. wed

32. mirod

33. butit

34. occupled

35. ondered

36. tabulated

37. taught

38. replied

39. trusted

40. preserved

47. arake

42. descended

43. vrote

14. drank

45. antled

46. repeated

47. ate

48. ceught

49. gulded

50. hunted
SWIITH

IT $\mathrm{T}$ W

B I W T I

H TWSIT

I I H I S

I Y

I T S H Y

WITSHY

IWITS

IHSIWI

SINI

TWYIHS

BSTIVI

S I I Y H

TIWIH S

THISIW

I WI H 5

S HITI

H I $\mathrm{T}$ S I I

TS I I U

I S T T

W T I IH

S T I I I

TISWYH

I $Y$ S H

WH T ISI

ISIHTW

WH S I T I

ISTHI

Y T I $\mathrm{SW}$

A I S W T

SW T Y IH

T T I H W

I $\mathrm{S}$ Y

WI TI H $S$

I W S T Y

W Y T I H S

THI US

HSW T T I

S I H

I I T H

I $\mathrm{T} T \mathrm{HS}$

TIBSIW

I I T S H

W II I Y T S

H T I S W

I S T Y H

IT IYH S

S I Y TW H

TWS I I H $51_{\text {" Inspected }}$

52. closed

53. joumed

54. consoled

55. consulited

56. cooperated

57. decided

58. gave

59. Iooked

60. explored

61. $108 t$

62. atood

63. sent

64. entered

65. offered

66. persuaded

67. quoted

68. Iatsed

69. won

70. presented

71. turned

72. waved

73. approwched

74. loved

75. sewed

76. answered

77. pointed

78. drevesed

79. served

80. noticed

81. stopped

82. Iistened

83. wondered

84. reached

85. Jumped

86. olept

87. Iiked

88. knocked

89. located

90. threw

91. climbed

92. thought

93. walked

94. $\operatorname{ran}$

95. Jeughed

96. sew

97. heard

98. Pelt

99. believed

100. worked
I T $S$ I

SXITI

WITXIS

WIYHST

I U H T I

HIS I I

S H T I W

TS I W

HWIS I I

T S I I HI

บSIIII

IS HII

IHWS I

WISIIH

S T

I I SHW

I H 5 I

W 5 y

IV 证 5

HWIIS

STIBI

T I H S I

I I $\mathrm{IST}$

WH S I I $T$

HY I T

$S$ H I I T

I I WHS T

IHIVIS

琵

IS S Y

H I $\mathrm{SWI}$

$S I H T Y$

TWSIHY

IIIS $\mathrm{IW}$

YWHIST

SH T I I

ISI HW

HISWTI

I H W I T

I S I I H

H I I Y S

SIWIRT

WIHSTI

IWTHST

I HS I I W

THIHSI

I I S T $\mathrm{T}$

WS TIY

I TIWH

SWIHII

Oporant Rate

Condsticuing 
1. Did you usually give the first sentence which cane to your mind?

2. How did ros go ahow deciling wheh of the words to use?

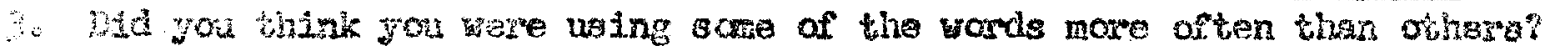

Which rards?

Why?

4. What did you think the purpose of this was?

5. While goling through the cards did you think that you were supposed to make up jour aentences in any particular way?

6. Did you get the reeling that you were supposed to change the in which you mode up Jour sentences? How?

?.

(If subject mentions $\mathrm{E}$ 's saying "m-hming $7-9$ ere not asked.)

7. Were you aware of anything about we?

8. Were you aware that I said enything? (If yes, 8 not asked) (Control ends here)

sctualy I did occasionally say "m hm." Thinktng beck now to when yon reve Folng through the cards, do you rember ay saying "mm han"?

20. What asd gayph "yon mean to you?

12. Did you try to figure cut what made we say "m hrun" or why ar whan I was saying "zon hroe"?" (If S says no, question it followa.)

12. How hard would you say that you tried to flgure out what was making we say "Iran ham" : very hards fairly hard; not hard at all.

33. What idess did you have about what was waking me say "Jum hern."

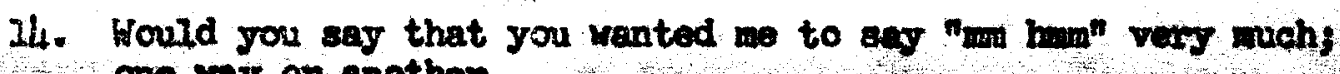
one vay or another.

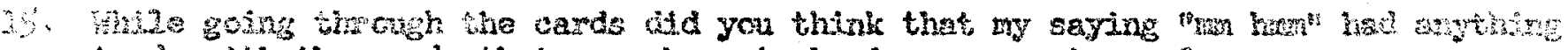
to co uthin tho words that jou chase to begin your tentences?

\section{What?}

16. Did you ever wre the tlea that I was saying "mom hw" after centences boginning with I or ted?

(If $S$ verbalises a correct contingency at any time during the intervlew, the abore schedule is discontinued and the folloning questions are asked.)

a. Is that sowething that you were actually anare of while going through the cards or is it something you thought of fust now?

b. Do you remenber when, while going through the cards, that idea occurred to you?

c. Did the fact that you realized this have any effect on the way in uhich you made up your sentences? In other vords, did you try and make up your sentences In thet way because I was saying "m ham"? 
BIPOLAR DESCRIPTIONS OF SOURCE TRAITS FCR CATTELL'S 16 PERSUNALITY FACTOR QUESTIONMA IRE - FACTORS A THRCOCH Q4

High Score

Factor A: Cyclothymia, (harm, Sociable) Good Natured, Sasy Coing

Ready to Cooperate

Attentive to Feople

Soft-Hearted, Kindly

Trustful

Adaptable

Warm Hearted

Factor B: Intelligence

Conscientious

Persevering

Factor C: Emotional Stability or Ego Strength

Emotionally Mature

Emotionally Stable

Calm, Phlogmatic

Realistic about Iffe

Absence of Neurotic Fatigue Flacid

Factor E: Dominance or Ascendance

Independent Minded

Hard, Stern

Solemn

Unconventional

Factor f: Surgency

Enthus Last1c, Happy-go-Iucky

Talkative

Cheerful

serene

Quick and Alert

\section{Low Score}

Sohizothymie (Aloof, Stiff)

Aggressive, Grasping, Critical

Obstructive

Cool, Aloof

Hard, Preclse

Suspicious

Rigid

Cold

Mental Defect

of Lover Marale

Quitting

Dissatisfied Emotionality

Lacking in Frustration

Tolerance

Changeable (In attitudes)

Showing General imotionality

Evasive (on awkward issues and

in facing personal dectsions)

Neurotically Fatigued

Worrying

Sulmission

Dependent

Kindly, Soft-Hearted

Expressive

Conventional

Desurgency

Glun, Sober, Serlous

Silent, Introspective

Depressed

Concerned, Brooding

Languid, Slow 
Factor G: Character or Super-Ego Strength

Persovering, Determined

Responstble

Consistently ordered

Factor H: Farmia

Adventurous, Likes Meeting Feople

Actire, Overt Interest in Opposite Sex

Reaponsive, Genial

Friendly

Carefree

Factor Is Premsia

$$
\begin{aligned}
& \text { Demanding, Impatient, } \\
& \text { Subjective } \\
& \text { Dependent, Seeking Help } \\
& \text { Acts on Sensitive Intuition } \\
& \text { Attention-Seeking }
\end{aligned}
$$

Factor L: Frotension

Jealous

Self-sufficient

Suspicious

withdrawn, Brooding

Tyrannical

Factor $M:$ Autia

$$
\text { Unconventional, Self-absorbed }
$$

Frivolous, Immature in

Practical Judgent

Interested in Art, Theory,

Basic Bellefs

Imaginative, Creative

Factor N: Shrewdness

Sophisticated, Polished

Socially Alert

Exact, Calculating Mind

Insightful Regarding Self

Insightful Regarding Others

Ambitious, Fossibly Insecure
Lack of Rigid Internal

Standards

Quitting, Fickle

Frivolous

Fielaxed, Indolent

Threctia

Shy, Withdrawn

Ret1ring in Face of opposite Sex

Aloof, Cold, Self-Contained Apt to Be imbittered Careful, Considerate

Harria

Reslistic, Expecto Littie

Self-reliant, Taking responsibility

Acts on Fractical, Logical cividence

Self Sufficient

fielaxed Security

Accepting

outgoing

Trustful

Open, Ready to Take a Chance Understanding and Permissive

Praxernia

Conventional, Alert to

Practical Needs

Sound, Realistlc, Dependable,

Pract1cal Judgment

Interests Narrowed to

Imnediate Issues

No Spontaneous Creativity

Naivete

Simple, Unpretentious Socially Clumsy and "Natural" Vague and Sentimental Mind Lacking Self-Insight

Unsillled in Analyzing Motives Content with what Comes 
Factor 0: Guilt Proneness

Worrying, Anxious

Depressed

Sensitive, Tender, Easily Upset

Strong Sense of Duty

Factor $Q_{1}$ : Fadicalism

Factor Q2: Selfasufficiency

Factor Q3: High Self-Sentiment Formation Controlled, Exaoting W1Il Power

Factor Q4: High Ergic Tension

Tense, Excitable
Confident Adequecy

Self-Confident

Choerful, Reallient

Tough, Placid

Expedient

Conservatian of Temperanent

Group Dopendency

Poor Self-Sentiment Formation Uncontralled, Lax

Low Ergie Tension

Fhlegmatio, Composed 
PERSONAL REACTION SCKEDULE

Anxiety Type M (Notor Tension)

Type $M$ anxiety is characterized by concern with external achievements coupled with physical tension vich acts as a defense against feelings of inadequacy. When frustration occurs, energy is channeled somatically instead of psychically. Type $M$ anxiety results in hyperactirity, physical and mental restlessness, or jumpiness.

A raiety Type O (Object)

Type 0 anxiety is characterized by concern that external demands and perceived expectancies may be over-whelming and one may suffer harm. It represents a projection or rationalization of one's possible personal inadequacy. It results in a magnification of personal problems out of proportion to objective reality. The amphasis here is on the external as a source of uncertalnty or unrest.

Anxiety Type $P$ (Personal Inadequacy)

Type $P$ anxiety is characterized by concern that one may not be capable of meeting the difficulties of life. The person hinself feels inadequate and the inadequecy lies within himself. There is a certain helplessness and self-evaluation which may give rise to guilt feelings. The focus of the uncertainty is on one's own Inadequacy. 


\section{APPROVAL SHEET}

The thesis submitted by Sister M. Austin Doherty, 0.S.F. has been read and approved by three members of the Department of Psychology.

The final copies have been examined by the director of the thesis and the signature which appears below verifies the fact that any necessary changes have been incorporated, and that the thesis is now given final approval with reference to content, form, and mechanical accuracy.

The thesis is therefore accepted in partial fulfillment of the requirements for the Degree of Master of Arts.
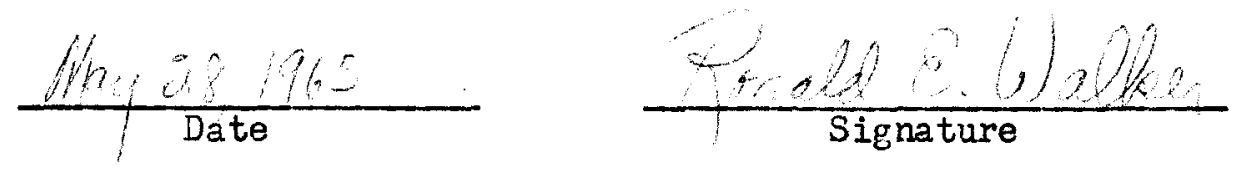